\title{
La Filosofía Ambiental y su Influencia en la Ciudad.
}

The Environmental Philosophy and its Influence on the City.

Por: Dr. Claudio Rafael Vásquez Martínez' y Dr. Jorge Téllez López

Recibido: Noviembre 2009

revisado: Noviembre 2009

aceptado: Diciembre 2009

Resumen: El presente articulo pretende presentar la equivoca y distorsionada relación de la persona con la naturaleza, basada principalmente en el poder y la explotación no sobre el deseo de entender que son en realidad la naturaleza, que tipo de comunicación puede existir entre las personas y el resto de la naturaleza, el valor intrínseco de la naturaleza y la conciencia animal. La idea prevaleciente es la concepción creada por las ciencias naturales, la tecnología, la sociedad industrial y la economía, según la cual la naturaleza es sólo una reserva de materia prima a disposición de la a persona. Se trata a la naturaleza y los animales en forma diferente a lo que es su esencia real. Por ejemplo un cerdo o una vaca se ven sólo como un vehículo de producción. Lo que interesa a la sociedad moderna en el cerdo es el porcentaje de grasa, el valor nutritivo y la calidad de la carne. No nos interesamos en el cerdo como un animal sintiente y consciente con una alma diferente.

Palabras claves: medio ambiente, comulación, conciencia, sentido, relación hombre naturaleza.
Abstract: This current article aims at showing the wrong and distorted relationship of the person with nature, based mainly on the power and the exploitation, not with the interest of understanding what really nature is, what type of communication may take place among people and the rest of nature, the intrinsic value of nature and the animal consciousness. The prevailing idea is the conception created by the natural sciences, technology, the industrial society and the economy, according to which nature is just a reserve of the raw material the person can benefit from. Nature and animals are treated differently from what their real essence is. For instance, a pig or a cow is seen as a production vehicle. What the modern society is interested in is the percentage of fat the pig has, the nutritional value and the quality of the pork. We are not interested in the pig as an animal that has feelings and consciousness, with a different soul.

Keywords: Environment; Comulation; Consciousness; Sense and Man-Nature Relationship.

'Profesor Investigador Titular "C"; U. de Guadalajara-México

"Profesor Investigador Titular "C"; U. de Guadalajara-México 
La filosofía en general está considerada como centrada en el ser humano, y los filósofos tratan temas relacionados a la persona. Aquellos que están interesados en la naturaleza y los animales normalmente estudian biología, ciencias veterinarias o ingeniería forestal. El bosque, las montañas, las playas, las llanuras, los ríos son principalmente lugares para experiencias estéticas. En el bosque, las montañas, las playas, las llanuras, los ríos, uno puede encontrar la clave para la relación con la naturaleza y los animales. El valor intrínseco de la naturaleza y la conciencia animal. El punto de partida es una concepción intuitiva fuerte sobre que el concepto actual de la realidad es erróneo. La idea prevaleciente es la concepción creada por las ciencias naturales, la tecnología, la sociedad industrial y la economía, según la cual la naturaleza es sólo una reserva de materia prima a disposición de la a persona. Se trata a la naturaleza y los animales en forma diferente a lo que es su esencia real. Por ejemplo un cerdo o una vaca se ven sólo como un vehículo de producción. Lo que interesa a la sociedad moderna en el cerdo es el porcentaje de grasa, el valor nutritivo y la calidad de la carne. No nos interesamos en el cerdo como un animal sintiente y consciente con una alma diferente.

Se ha permitido a la tecnología y al poder económico y a diferentes grupos de interés definir que es la naturaleza. Se cree que estas definiciones están lejos de la realidad. El bosque se vende en forma de libros interesantes y bellos muebles. El bosque no es visto como un producto final, ha sido separado de su origen. Esto también se relaciona con los productos cárnicos en los negocios. Ya no se compra cerdo, se compra costillas o jamón o bifes.

Inherente tanto al capitalismo como al comunismo es la idea básica de que los recursos naturales son gratis. Se considera que un recurso natural se vuelve valioso sólo a través de la actividad humana. La persona ha sido capaz de obtener recursos humanos para su refinamiento, y no ha necesitado nunca compensación alguna. El bosque, las montañas, las playas, las llanuras, los ríos, las rocas y los animales han existido para la persona.

En Puerto Vallarta se vio destruido el ambiente natural. Se construyeron caminos, mercados y casas residenciales en el bosque, las montañas, las playas, las llanuras, los ríos. No se ve ningún valor agregado en el asfalto y las construcciones. Se ve como un empobrecimiento. El bosque, las montañas, las playas, las llanuras, los ríos eran más valiosos que las construcciones humanas. Para Aristóteles considera que el valor intrínseco de la naturaleza es imposible, porque la naturaleza pertenece a la esfera de las ciencias naturales y los valores se generan con la actividad humana. La naturaleza se considera como vacía de valores, sólo los seres humanos pueden tener valores. Se distingue entre valores intrínsecos antropocéntricos (centrados en la persona) y naturocéntricos (basados en la naturaleza). Ambos involucran valores humanos, pero los valores intrínsecos naturocéntricos son aquellos asignados por los seres humanos a la naturaleza, como siendo intrínsecos a la naturaleza, la naturaleza es valiosa así misma. Se puede dar al bosque, las montañas, las playas, las llanuras, los ríos un valor instrumental o un valor intrínseco.

Existen dos concepciones opuestas: ó los valores se originan en la cultura humana (valores antropogénicos) o los valores se generan en el curso de una larga evolución incluso antes de la era humana (valores naturogénicos). 
Según el pensamiento naturogénico, los valores no existen sólo en la persona, sino en las plantas, los animales e incluso los ecosistemas. Un punto de partido más natural para encontrar valores es buscar en los animales. Un valor central que se encuentra en los animales es el sufrimiento. El sufrimiento tiene un propósito definido en la naturaleza: aumenta las probabilidades de supervivencia de los animales, y la idea inversa del sufrimiento es el bienestar. El ser humano puede pedir el bienestar animal, sin embargo, no está creado por la persona, es un tema de bienestar o sufrimiento del animal mismo.

Se considera que la idea de que sólo los seres humanos pueden tener valores es artificial. Para el jaguar, el conejo posee un valor instrumental como presa que mantiene la vida y el bienestar del jaguar. El mismo jaguar puede considerar a sus miembros como animales con valor intrínseco y no los trata como meros instrumentos. Los animales crean valores independientemente de lo que los seres humanos piensen sobre ellos.

Referente a los valores de las plantas. Que una planta hogareña prospere o no depende de las personas, sin embargo el buen o mal estado es la calidad propia de la planta. El problema surge también de la pretendida falta de yo en las plantas. Si una planta no tiene yo, żqué es lo que prospera o sufre?. Esto requiere una nueva forma de pensar.

Los valores ecogénicos: ¿̇pueden los sistemas poseer valores que no pueden rastrearse a partir de los individuos? La tradición filosófica relaciona a los valores con los individuos y por lo tanto no puede comprender que una montaña, una playa, una llanura, un río, puedan poseer un valor intrínseco. Se presenta la pregunta de si la naturaleza como un todo puede ser un sujeto con una conciencia holística y si una montaña, o una playa, o una llanura, o un mar, o un río pueden tener experiencia.

Aquí se observa un mundo de experiencias que difieren por completo del mundo de experiencias humanas. Lo que hace a la persona no pueda desprenderse de la respuesta a los tres problemas fundamentales de toda filosófica: ser, mundo, vida. Estas respuestas las busca la "teoría", que indaga las causas últimas y los primeros principios, esto es lo que se conoce como filosofía.

El ser humano es un ser teleológico y axiotrópico, orientado a sus fines esenciales, para lo cual escoge, aprecia y vive ciertos valores de alguna manera jerarquizados. Ese vivir sabio (phrónesis) rige tanto la vida individual (ética) como colectiva (política). Sabiduría entendida como armonía interior y capacidad de valorar y escoger entre el bien y el mal, contrariamente a la idea de sabiduría como erudición enciclopédica.

Esta capacidad de escoger entre el bien y el mal forma parte de una visión globalizante que toda persona tiene de la realidad, que se conoce como "Weltanschauung" (cosmovisión, visión del mundo) que es la forma en que se intuye toda la realidad penetrada por conexiones vitales, llenas de sentido. 
Una "Weltanschauung" implica tener una idea acerca del cosmos, del ser y de la persona, sea cual fuese dicha idea, entendida como una totalidad, dentro de la cual se destaca la idea acerca de lo que la persona es, su misión y destino, causa y naturaleza esencial. De ahí que de acuerdo a la idea de la naturaleza humana que se adopte se presupondrá una idea respecto a lo que la persona es capaz de apreciar, saber y hacer. Detrás de cada idea hay una idea de la persona que es capaz de hacer ciencia, entendida como todo coherente de conocimientos verdaderos. Si se considera que la persona es capaz de conocer sólo los fenómenos percibidos a través de sus sentidos, el conocimiento válido será solo aquel que se aprehenda por la vía sensorial y el conocimiento discursivo será considerado mera fantasía. Distinta será la idea del conocimiento si se acepta que la persona conoce por la razón y por los sentidos. De ahí que la "Weltanschauung" que se adopte inspirará toda idea de la persona y de ciencia y estas a su vez se traducirán en conocimiento técnico y acción.

El ambiente es un conjunto de condiciones que afectan la existencia, desarrollo y bienestar de los seres vivos. No se trata de un lugar en el espacio solamente sino de todas las condiciones físicas, químicas y biológicas que favorecen o no el desarrollo.

Los ambientes son naturales o artificiales. Los primeros no han sufrido la intervención de la persona. En general son ambientes estables, en el sentido de que poseen poblaciones de especies vegetales y animales (herbívoros, predadores y descompositores) viviendo en perfecto equilibrio. El ambiente artificial es aquel que fue modificado por la persona, generalmente con el propósito de favorecer el desarrollo de una o pocas especies vivientes en particular. Es el caso de las áreas cultivadas, en las que se procura obtener las condiciones de suelo, humedad, etc., favorables para el desarrollo de ciertas plantas. Las plantas concurrentes son sistemáticamente combatidas como "hierbas dañinas" y los herbívoros, consumidores naturales de esas plantas, también son transformados en tanto que "plagas de la agricultura". Así opina S. Miguel. Branco ', otorgando el ambiente un vaivén conceptual que va desde un conjunto más o menos vago de "condiciones" relativas a los continentes, cual actitud no es sólo espacial, a los contenidos de los ecosistemas, ya originarios, ya intervenidos por la persona.

Esta ambivalencia "afuera-adentro" revela el juego dialéctico existente entre los seres y su entorno, que no es y que a un tiempo es parte de los mismos.

El ambiente de las comunidades humanas, empero, no es ni totalmente natural, ya que contiene formaciones socioeconómicas dotadas de cultura, por tenue que ésta sea desde el punto de vista ergológico o tecnológico, ni totalmente artificial puesto que la persona somática es tan natural como una abeja o un eucaliptus. El ambiente es un sistema de medios que interactúan entre sí. Cuando el medio natural es intervenido por la persona no se convierte por ello en un medio artificial; cuando la persona construye por completo el contorno- una fábrica, una ciudad tampoco ese medio es del todo artificial puesto que no ha sido elaborado por un deux ex machina sino por una criatura viviente, o mejor, parafraseando a Marx, por un conjunto de criaturas vivientes llamadas obreros cuyo trabajo cooperativo obtiene resultados mucho más intensos y valiosos que el puro trabajo individual. Por otra parte no se puede prescindir del aire, 
del agua, de la presencia siempre constante de la naturaleza, actora en o escenario del teatro humano.

Los seres vivos están rodeados de entes materiales y energías que constituyen su ambiente, mediante los cuales satisfacen sus necesidades vitales, siendo por ello insoslayable su estrecha relación con cuanto les rodea. Todo organismo precisa para conservar la vida una continuada aportación de materia y energía, que sólo puede obtener mediante el intercambio con el mundo circundante. Ningún animal ni vegetal pueden vivir aislados por completo gracias a su piel impenetrable o a su consistente caparazón sino que, por el contrario, necesitan: a) incorporar energía del medio; b) incorporar diferentes materiales; c) eliminar los productos residuales. Tal intercambio del organismo con el ambiente puede considerarse como una "fisiología externa" que reviste la misma importancia que el adecuado funcionamiento de los mecanismos fisiológicos internos. La acción del ambiente no está limitada al simple suministro de materia y energía a los seres vivios para colmar sus necesidades vitales. Como quiera que los animales o vegetales tienen, por así decirlo abiertas sus fronteras al comercio exterior, pueden penetrar dentro de ellos materias nocivas o sufrir influencias desfavorables. Para que un organismo pueda vivir el ambiente debe, pues reunir dos condiciones: a) proporcionar un mínimo de requisitos indispensables para la vida; b) no contener ninguna condición desfavorable para aquella.

Así se expresa Clarke ${ }^{2}$, quien agrega que los ambientes están constituidos no sólo por elementos abióticos sino por otros organismos. Aparece aquí de nuevo el carácter intersticial del ambiente. Pero Clarke agrega luego un nuevo concepto: el factor físico del ambiente que debe considerarse en primer lugar es el medio, entendiendo por tal la materia que rodea inmediatamente al organismo y con la cual éste mantienen importantes intercambios. El único medio que considera Clarke es el natural y aún así los organismos no tienen mucho que elegir: el agua o el aire son las alternativas que conforman dicha polaridad. El medio agua y el medio aire proporcionan las bases fundamentales de la a vida, en las cuales figura preponderantemente el oxígeno, ya en la combinación $\mathrm{H}_{2} \mathrm{O}$, ya como un gas mezclado con otros gases. Pero hay que tener en cuenta las interfases: hay varios gases atmosféricos disueltos en el agua y dentro de la atmósfera el agua se manifiesta como componente higrométrico de aquélla. Finalmente se debe distinguir entre medio y sustrato. Si bien para algunos ecólogos no hay diferencia entre ambos para Clarke sí la hay: "parece más lógico emplear la palabra medio exclusivamente para designar el material que rodea al organismo de manera inmediata, y sustrato únicamente para las superficies o materiales sólidos del ambiente sobre o dentro de los cuales vive el organismo" ${ }^{3}$.

Hay conceptos de ambiente ceñidos a una noción fiscalista que debe suponerse también inorgánica, tales como el siguiente: "las plantas y los animales que viven juntos, más la parte del ambiente físico con el que actúan en reciprocidad, constituyen un ecosistema" ${ }^{4}$. Sin dejar de advertir que esta incompleta y estática noción de ecosistema llevaría a cualquier estudiante de secundaria a una segura reprobación, cabe señalar que los autores centran su interés en aquél, dejando de lado los refinamientos conceptuales. El ambiente en tanto que "medio ambiente físico" es empobrecido y tergiversado al tiempo que el ecosistema se convierte en un paradigma integrado por la reciprocidad actuante de plantas, animales y ambiente, con todo lo que tiene 
de anacrónico hablar de plantas y animales cuando el empleo del modesto concepto de biocenosis podría haber obviado este resabio decimonónico de los Turk y los Wittes.

Un botánico con entrenamiento ecológico, lo cual no lo emancipa de su especialización pues la ecología está más allá de los "reinos", revela una buena puntería conceptual: Un medio es la suma de influencias o fuerzas externas (por ejemplo, el calor) que afectan la vida de un organismo. Cada individuo tiene una historia medioambiental particular y diferente a la de cualquier otro individuo. Nuestro propio medio ambiente cambia continuamente en el tiempo y en el espacio [...] Un sistema ecológico consta de un componente biológico central formado por uno o más organismos y el medio con el cual dichos organismos interactúan y el cual reciben energía [...] Todos los organismos desempeñan dos papeles: como partes del centro vivo del sistema y como partes de su propio medio ambiente [...] Un medio ambiente ocupa un espacio tridimensional y se extiende a lo largo del tiempo. Pero esto no significa que el medio ambiente sea uniforme a través del espacio y del tiempo. Por el contrario, el medio ambiente natural siempre muestra gradientes verticales y laterales en su dimensión espacial y en su dimensión temporal refleja los poderosos ciclos diurnos y anuales de radiación solar. Un medio ambiente es un complejo de muchos factores que interactúan no solamente con los organismos sino entre ellos mismos. Como resultado de ello es difícil aislar una parte del medio y cambiarla sin afectar a otras partes del medio a mbiente. Algunos ecólogos dividen el medio ambiente en dos partes: el medio físico y el medio biológico. en cierta forma esto es un tanto artificial, puesto que el medio actúa como un sistema complejo y único y los efectos que otros organismos producen en el medio generalmente se expresan y perciben por medio de factores físicos. ${ }^{5}$

Si bien esta definición confunde medio con ambiente y recurre al centauro conceptual medio ambiente, lo cual es una falta menor, destaca los aspectos espaciotemporales con mayor intensidad que las otras.

Un antropólogo, luego de afirmar que la cultura es "la parte del ambiente hecha por el hombre", efectúa el siguiente análisis: Hábitat designa el escenario natural de la existencia humana, las condiciones físicas de la región habitada por un grupo de gente, sus recursos naturales, real o potencialmente a su disposición; su clima, altura y otras condiciones geográficas a las que se ha adaptada.

Cultura, tal como se emplea (por el autor) [...] se refiere a aquella parte del ambiente total que comprende los objetos materiales de manufactura humana, las técnicas, las orientaciones sociales, los puntos de vista y los fines consagrados que constituyen los factores inmediatos condicionantes en que se cimenta la conducta.

Ambiente, por consiguiente, cobra su plena significación etimológica, la del diccionario: "El agregado de todas las condiciones e influencias externas que afectan la vida y el desarrollo de un organismo", en este caso el hombre en su escenario natural y cultural"' ${ }^{\text {. }}$. 
Según este concepto el ambiente es el resultante del cruce de esos medios: el natural, como soporte fisiográfico puro, y el artificial, donde se vierten los aspectos visibles e invisibles de la cultura humana, aparentemente reducida, "behaviorísticamente", a mera conducta. El esquema es demasiado rígido pues en ningún momento Herscovits recurre a la idea de sistema y sí a la de agregado. Por otra parte la persona, si bien como homínido es un organismo, como humánido es un creador y portador de valores sociales, artísticos, religiosos, morales, políticos, etc. La cultura no es solamente una influencia externa: una vez internalizada desafía a las ominosas influencias externas como lo demuestran los hombres que murieron en la hoguera por no abjurar de sus creencias y los emigrantes que, como los caracoles, marchan con su fardo cultural a cuestas y lo imponen o defienden cuando se asientan en otro hábitat y colisionan con otra cultura.

De todos modos el concepto de este autor no es desdeñable y, mejor elaborado, podría ayudar a comprender el juego de los subsistemas socioculturales en los ambientes concretos.

Un geógrafo, sin apartarse de las anteriores concepciones, enriquece la noción de medio y le concede un dinamismo que otros científicos no tienen en cuenta, seducidos por el estatismo de los modelos: El medio ambiente es, al mismo tiempo, un medio y un sistema de relaciones [...] el medio ambiente es el conjunto de las bases y los equilibrios de aquellas fuerzas que rigen la vida de un grupo biológico ${ }^{7}$.

En una definición que tanto gramatical como conceptualmente resulta desamparada y asimétrica, un renombrado economista dedicado últimamente al estudio de los problemas ambientales desde la biblioteca de la CEPAL dice "El ambiente es el ámbito físico natural y sus sucesivas transformaciones artificiales así como su despliegue espacial" ${ }^{8}$. Acá no hay noción de sistema, la redundancia de la nota de "despliegue espacial" es manifiesta y la secuencia ambiente físico natural + sucesivas transformaciones artificiales no acentúa como es debido a los aspectos antroposociales del ambiente. En todo ambiente existe un fenosistema sensible, perceptible, mensurable, que se despliega en conchas concéntricas de espacios significativos, y un criptosistema simbólico que no solo yace tras la forma, la función y el intervalo de las cosas en el espacio sino que califica la extensión física con la evaluación social, lo que supone incorporar el tono de pathos cultural y los acentos invisibles de lo permisible y lo prohibido, lo sagrado y lo profano, lo público y lo privado, etc., a los meramente corpóreo. Un ambiente, también registra los precipitados de la historia en el cuerpo estructurado del espacio que de pasivo se torna en activo, configurando de tal modo una trama de precipitados y dispositivos donde el tiempo se encarna y escalona. La dimensión temporal no pede ser disociada ende los ambientes que se perciben de modo espontáneo o son analizados con deliberada actitud científica: la del urbanista, la del ecólogo, la del sociólogo, etc. 
La Filosofía Ambiental y su Influencia en la Ciudad.

\begin{tabular}{|c|c|c|}
\hline $\begin{array}{l}\text { Ambiente } \\
\text { Físico } \\
\text { Relaciones } \\
\text { Hombre-objetos }\end{array}$ & \begin{tabular}{|l|}
$\begin{array}{l}\text { Posibilidades de experiencia } \\
\text { (contacto unilateral) }\end{array}$ \\
1 \\
mirar edificios y \\
espacios urbanos
\end{tabular} & $\begin{array}{l}\text { Posibilidades de actividad } \\
\text { (contactos bilaterales) } \\
2 \\
\text { dormir en la casa } \\
\text { vivir en la ciudad }\end{array}$ \\
\hline $\begin{array}{l}\text { Ambiente } \\
\text { Social } \\
\text { Relaciones } \\
\text { Hombre-hombre }\end{array}$ & $\begin{array}{l}3 \\
\text { escuchar a la gente } \\
\text { tocar a la gente }\end{array}$ & $\begin{array}{l}4 \\
\text { intercambiar ideas } \\
\text { convivir con la esposa }\end{array}$ \\
\hline
\end{tabular}

Modelo normativo de la persona en el ambiente (según J. Gehl)

Un teórico de la arquitectura ofrece un modelo de ambiente urbano que puede aplicarse a cualquier otro que no lo sea. Gehl considera que todo ambiente está formado por nuestros semejantes, por objetos (artefactos fabricados por los seres humanos) y por las expresiones de la naturaleza-inorgánica, biológica-que constituyen una realidad distinta a la de los seres humanos.

Nuestros semejantes proporcionan el ambiente social. El ambiente físico está constituido por todo lo demás, excepto la gente. Se puede así experimentar (percibir) en parte el ambiente físico y en parte a la gente, sus voces, su presencia, etc. Esto es lo que se podría denominar un contacto unilateral. Pero también se puede permitir que la experiencia (percepción) del ambiente físico conduzca a la acción. Por ejemplo, se pueden usar los objetos. Nuestras experiencias con nuestros semejantes también pueden conducir a una actividad junto con ellos. La condición para que esto suceda es que se establezcan contactos bilaterales. De acuerdo con el modelo se tienen cuatro tipos de situaciones diferentes [...] El modelo es más bien burdo, No cubre la gran variedad de tonalidades que ocurren en la vida real, pero para los fines propuestos es bastante explicativo?.

Para finalizar con las definiciones y conceptos de ambiente, que con ser incompleta alcanza para cubrir nuestro objetivo, se ofrece la de un ecólogo con buena formación matemática y reconocida experiencia en la construcción de sistemas:

... En su forma más funcional y exacta el medio ambiente de un biosistema puede definirse como un conjunto de variables o factores no pertenecientes al biosistema que están acoplados a elementos o subsistema del biosistema. Tales variables ambientales pueden conceptualizarse como originándose en un sistema o sistemas ambientales. Las variables que definen el medio 
ambiente del biosistema son aquellas que se encuentran directamente acopladas a elementos del biosistema; en sentido estricto; las variables que influyen en dichas variables ambientales (a nivel de resolución adoptado) no forman parte del medio ambiente del biosistema. En principio, sólo revisten interés en la medida que contribuyen al comportamiento del biosistema examinado 10 .

Esta es una conceptualización correcta de ambiente si bien de naturaleza sumamente abstracta. Emplea la terminología que emerge de ese compromiso de los matemáticos obligados a renunciar, para ser accesibles al lector común, a los signos del álgebra o a los jeroglíficos de la lógica simbólica; al dirigirse a un público no iniciado en sus lenguajes y metalenguajes utilizan una entonces verbalización vaga, no específica, que, por ceñirse a lo obvio, parece no decir nada significativo.

Un ambiente es aquella porción de la realidad que tiene relacione recíprocas y dialécticas con los seres $u$ objetos cuya presencia intercalar determina su existencia. Las definiciones anteriormente analizadas nos autorizan para hacer esta afirmación pero no nos aclaran que es la realidad. Y como la categoría filosófica de realidad es elusiva y controvertible conviene que dediquemos a su examen un parágrafo especial de nuestro estudio.

\section{La realidad cambiante.}

Los sistemas materiales a los que se viene refiriendo - los biosistemas, los sociosistemas humanos y los tecnosistemas objetivados-forman parte de la realidad local del planeta Tierra pues la realidad entera y completa abarca la totalidad del Universo. Dentro de la Tierra también cabe distinguir dónde hay condiciones para la vida de los ecosistemas y los antroposistemas y dónde no los hay. La ecumene deslindada por Ratzel a fines del siglo XIX es la zona donde la vida y la civilización son posibles; la antiecumene, la zona donde aquéllas no pueden prosperar: el interior de la Antártida, la cima del Everest, las áreas desérticas más rigurosas del Atacama.

El Universo, de uni-versum, el uno donde todo se vierte, el gran vertedero y la totalidad de lo vertido, los astros y el espacio que los separa y contiene, es el to pan de Aristóteles (metafísica, V. 26:1023 b) y nos remite a la idea de un conjunto aún desordenado donde los cuerpos, el tiempo y el espacio conservan la importancia del Chaos inicial, es decir, del abismo. Dicho Universo se convierte en Cosmos (mundus en latín) cuando aparece un principio de orden, cuando se instaura una jerarquía, cuando surge un armonioso diálogo entre los contenidos y continentes. Este equilibrio es alabado por Platón (Gorgias, V:508) de esta manera: Dicen los sabios, amigo Calicles, que la sociabilidad, la amistad, el buen orden, la prudencia y la justicia mantienen unidos Cielo y Tierra, dioses y hombres, y por esta razón llaman Cosmos (orden) a todo ese conjunto, y no desorden ni intemperancia.

El pan indiferenciado del Universo se convierte, ya por obra divina, ya por la mirada o la mano ordenadora del hombre, en Cosmos, en sistema en un todo ordenado y bello que es más que la 
sumatoria de las partes. Es entonces un holon y de aquí provienen lo holístico que los partidarios del enfoque sistemático procuran, partiendo del organismo, proyectar donde la materia define sus formas. De esta manera, gracias al soplo del orden, el Universo, el receptáculo-de-todo y el todo-en-un receptáculo, se transforma en el Universo-mundo. Dicho Universo-mundo rechaza lo in-mundo, lo desliñado, las intrusiones de la contaminación o la impureza, lo que no cabe en los puestos asignados dentro del túnel luminoso que atraviesa la oscuridad, que organiza las nociones de espacio y tiempo, que libra de la angustia. Acá cobran su verdadero significado los conceptos de Hybris, la desmesura, y de sophrosyne, el equilibrio cabal y sereno. Se establece así la presencia de lo deontológico-lo que debe ser-, de lo normativo -lo convencional, lo acordado entre los hombres-, de los valores establecidos por una voluntad superior (Dios, el Creador, el Primer Móvil, el Nombrador, el Demiurgo), o extrapolados por el sujeto actuante y pensante a su ambiente, para legalizarlo y hacerlo inteligible. La ley moral es la madre de la ley física: la polis se proyecta en el Universo y lo transforma en Kosmos; el nomos da sentido a la phycis; el mythos tribal y rústico deja paso a la filosofía, hija de la ciudad".

Los ambientes dialécticamente vinculados con las biocenosis y las antropocenosis tienen distintas escalas, según sea el punto de vista escogido por el observador. Así existe el ambiente del microecosistema instalado en el interior de las flores gigantescas, como sucede en la isla de Trinidad, y el ambiente de una gran ciudad como México. Los ambientes, cuantificables y calificables, son parcelas significativas de la biosfera, la delgada piel de nuestro planeta cuyo espesor, de convertirse en una pasta homogénea, sería de unos cuantos centímetros sobre la superficie terráquea (terra + acqua). Los procesos vitales de esta biosfera materna tienen lugar en las interfases del agua, la tierra y el aire, determinadas por la presencia del «fuego» solar. Agua, tierra, aire y fuego, los constituyentes de la tetralogía de Empédocles, fueron los elementos invocados por los magos y los alquimistas, custodios de la Tradición, y son, como lo había entrevisto el taumaturgo griego, las claves ambientales de la vida.

Los ambientes que se consideran relevantes, en tanto que marcos del género humano, consisten en constelaciones de realidades acotables, descriptibles, localizadas, concretas. A veces los ambientes se «encogen» hasta convertirse en microambientes como el existente en el interior de nuestro organismo. Luego se hallan mesoambientes y los microambientes, establecidos por la escala del cuerpo humano y por la proxemística social. Toda la física clásica es una proyección del hombre, como lo ha demostrado Bernal ${ }^{12}$. Y la metrología, hija de la antropometría, también resulta de la impronta espacial de las dimensiones humanas: pulgada, cuarta, codo, pie, yarda, braza, etc. ${ }^{13}$. Del mismo modo existen una distancia cultural para el diálogo, una dimensión social para el espacio de la sala, un área comunal para establecer las dimensiones del asentamiento humano face to face, tal cual surge de los interesantes estudios de Hall ${ }^{14}$.

Todos los ambientes anteriormente nombrados, cuya clave es la percepción antropotópica de los continente y contenidos espaciales, tiene que ver con lo que denominamos realidad. Pero ¿̇a qué realidad nos referimos? ¿A la que registran nuestros sentidos? ¿A la que se oculta detrás de las apariencias? ¿A la realidad de las cosas? ¿A la realidad de la mente que las aprehende y ordena? 
El científico práctico que se codea con los objetos materiales e investiga los fenómenos para "construir» los hechos subyacentes, acepta sin reservas la existencia de una realidad revelada por sus sensores fisiológicos o develada por instrumentos suprasensibles que, en definitiva, prolongan y afinan las informaciones obtenidas por los sentidos. Dichos sentidos exploran el ambiente del nicho ecológico o cultural donde habita el organismo, lo que conforma una rutina adaptiva, o salen al encuentro de los sistemas desconocidos, desorientadores, de los nuevos ambientes para iniciar el consiguiente proceso de adaptación a los mismos. Los estímulos sensoriales de la naturaleza mecánica, electromagnética o química constituyen el flujo del ambiente que los sentidos escogen, captan, tamizan y conducen a través de la red nerviosa hasta el cerebro. Solamente cinco sentidos nos guían en medio de la selva ambiental, cuya riqueza de mensajes es empobrecida por el pequeño repertorio los canales selectivos que exploran y registran el mundo exterior. Pero esa aparente pobreza se ve compensada por el sistema perceptual, que alquitara y combina las informaciones que ingresan a nuestro organismo, codificando y decodificando, según las instancias, la polifonía brotada de los ambientes habituales o inéditos. Sin caer ni en el determinismo de las especies sensibles al estilo de Hobbes ( «no existe ninguna concepción del humano intelecto que no haya sido recibida, total o parcialmente, por los órganos de los sentidos») ni en el idealismo de Berkeley («la realidad está constituida por los datos de los sentidos y no hay ninguna cosa que se encuentre más allá de dichos datos»), podemos decir que la información recogida por los sentidos constituye el único material con que cuenta la persona para aceptar, negar, formar y transformar la realidad substantiva que lo rodea. Los sentidos humanos son algo así como ventanas abiertas hacia el exterior y ofrecen una visión de dicho exterior sujeta a los registros topológicos de aquéllos. Las nociones de espacio y de tiempo dependen del pentágono sensible; nuestras concepciones del mundo se asientan en sus estrictas configuraciones. El olfato del perro y los ojos de la mariposa, traspasados a los hombres, ofrecerían un diseño distinto del entorno fenoménico. Y si se tuviera el oído del murciélago y su capacidad para registrar mediante ondas de un radar biológico las acechanzas de la lejanía y el corazón de las tinieblas, otra sería nuestra concepción del ambiente y por ende de la realidad.

La persona común y el científico confían en los datos de los sentidos que parecen dibujar en la mente, con trazos fieles, los perfiles del mundo en torno. Pero el filósofo es menos conformista, más artero y sutil. Demócrito y Leucipo, los atomistas de la antigüedad, consideraban que los sentidos sólo nos ofrecían un retablo de apariencias, en tanto que las realidades últimas estaban reservadas al juego de los átomos en el espacio. Pero ellos no fueron los únicos en discutir acerca de la veracidad o el error de los sentidos. Desde hace veinticinco siglos la filosofía del Occidente se empeña en definir la realidad y en su largo meditar sobre ella y sus fantasmas nos han legado conceptos múltiples y contradictorios. Empero, puede acordarse preliminarmente que la realidad es un modo de ser propio de las cosas en cuanto que ellas existen fuera de la mente del observador.

No obstante, hay que poner cuidado al enumerar las que efectivamente son cosas de la realidad. Por inevitable inercia, debida quizá a la impertinencia de los lazarillos acústicos, táctiles y ópticos que nos guían en el mundo que comienza más allá de nuestras epidermis, al 
referirnos a las cosas pensamos en entes concretos, sustantivos, espacio-temporales. Se trata del espectáculo de lo visible, de los volúmenes que se revelan al tacto, de los aromas que orientas hacia los pequeños espacios gratos o nos apartan de los rincones malolientes: manos, niños, sillas, flores, mingitorios. Esta suerte de cosas puede ser captada por los sentidos, inventariadas y comparadas por los buenos oficios de los receptores de información que nos acompañan desde la más remota infancia de nuestra especie. Dichas cosas son: aparentemente, realidades estáticas, conformadas por sistema supuestamente fijo de propiedades que coexisten en el espacio.

Sin embargo, los objetos tridimensionales donde confluyen la materia y la forma aristotélica no son las únicas cosas que habitan en el mundo. Hay además cosas atemporales y abstractas como los números, inespaciales y suprasensibles como la conciencia (desconocida por Skinner y sus secuaces), y aún, seamos adictos o no a la metafísica, cosas trascendentales, tal cual lo establecieran Kant y Hegel con el noumenos y el Espíritu. Todas estas cosas pertenecen a la realidad pues acaban revelándose cómo son luego de una previa búsqueda y un ulterior reconocimiento, y no como deberían o podrían ser.

Pero no pertenecen a la realidad ni lo concebido como el apocalipsis nuclear; ni lo probable como la extinción de los caimanes en la Amazonia; ni lo posible como el «efecto de invernadero» y el derretimiento de la criosfera o esfera de los hielos; ni lo fantástico como el Unicornio o la Medusa.

Bien decía Hegel que «el entendimiento común suele errar cuando considera como reales y efectivas cosas ideadas por la mente». Claro que estas «cosas» tienen a veces una potencia social avasallante:

recordemos si no aquel engendro de la «raza aria»-arios son los lenguajes, no la somatología- que en nombre del Volkgeist de la nación alemana señaló a los representantes de la «raza semita»

-tan inexistente como la aria, pues semíticos son los lenguajes - como responsables de la decadencia alemana (y para iniciar un «renacimiento» depurador los asesinó por millones).

Hasta ahora apenas se ha comenzado a indagar por la naturaleza que tienen las cosas de la realidad, la cual aparece ya como un continuo, si la mirada es sintética, ya como un conjunto relacionado de entes sumergidos en distintos contextos, si la mirada es analítica. Al consultar las publicaciones científicas acerca del ambiente de los biosistemas y antroposistemas comprobaremos que en los libros de «ciencia normal» y en los artículos - no todos- de «ciencia contestataria» se considera que las notas fundamentales del archipiélago de las cosas que se recortan sobre la homogeneidad de los distintos medios son su existencia, consistencia y resistencia, su extensión y discontinuidad formales, su dinamismo procesal, su temporalidad, sus interrelaciones dialécticas y su sistematicidad integrada en órdenes jerárquicos de cantidad y complejidad crecientes -ecosistema, bioma, biosfera-. Estas características, con leves 
variaciones, se repiten en el campo de las ciencias fenoménicas que estudian las cosas de la naturaleza, pero ayudan muy poco a atravesar el Rubicón de lo fenoménico, esto es, a develar la naturaleza de las cosas.

Si se comienza, al margen de la seguridad que tienen los científicos, a preguntar machacona y socráticamente por el verdadero ser de las cosas, por la realidad de sus relaciones, por su auténtico rostro y no por el maquillaje que lo disimula, se comienza entonces a asumir el papel de aguafiestas propio del filósofo. En efecto, las cosas tal cual son no se ofrecen gentilmente a los sentidos:

Los hechos [en verdad se debió decir los fenómenos], los datos, aún siendo efectivos, no son la realidad [...] Si para conocer el pensamiento no tuviera otra cosa que hacer sino reflejar una realidad que ya está ahí, en los hechos, presta como una virgen prudente esperando al esposo, la ciencia sería cómoda faena y hace milenios el hombre habría descubierto todas las verdades urgentes. Mas, acontece que la realidad no es un regalo que los hechos hacen al hombre [...] Los hechos por sí mismos no nos dan la realidad; al contrario, la ocultan, esto es, nos plantean el problema de la realidad. Si no hubiera hechos no habría problemas no habría nada oculto que es preciso desocultar, descubrir. La palabra con que los griegos nombraron a la verdad es alétheia, que quiere decir descubrimiento, quitar el velo que oculta y cubre algo ${ }^{15}$.

Como se anotó entre los corchetes, con evidente irrespeto al pensamiento de Ortega, existe un equivocado uso de la voz hecho en vez de la voz fenómeno. Porque hecho y fenómeno son relaciones con la realidad de distinto alcance y significado. En efecto, los hechos son los granos escondidos en la paja de los fenómenos. O mejor, y dicho metafóricamente, los hechos, invaginados en sistemas cuantitativa y cualitativamente más complejos - los peces grandes comiendo a los chicos, como en los cuadros de Brueghel el Viejo-, conforman la estameña de la realidad. En cambio tiene plena razón el filósofo español cuando dice que la realidad es evasiva. La realidad, efectivamente, oculta su faz tras el anti-faz de los fenómenos. La realidad está encubierta por el vestido de lo aparente - el titilar de las estrellas, la «salida» del Sol, el pez que nada bajo el agua ante nuestros ojos y no está materialmente en el lugar dónde lo vemos - y para descubrir su ser tras el parecer o el aparecer, que al cabo resultan un disimular, es necesario que el sujeto cognoscente realice una serie de operaciones mentales o instrumentales para convertir los fenómenos en hechos.

La conversión del fenómeno en hecho, de lo aparente en real. de lo dado en conocido, requiere una planificada y vigilante actividad de la mente. Es menester atravesar la corteza despistadora y a menudo engañosa que recubre con una proteica reverberación de fenómenos la sustancia recatada de la realidad. Para cumplir eficazmente esta tarea debemos recurrir a un taladro teórico que, además de buscar lo oculto, contribuya a la construcción del objeto como un pendant cognitivo del sujeto.

Se impone, entonces, apelar al empleo de «cierto lenguaje» como lo pedía Poincaré -ya como entrada en, ya como salida de- para metamorfosear con ecuaciones, símbolos o números, 
también metáforas de la realidad, la oruga elemental que surge de la observación a efectos de convertirla una crisálida, en un hecho científico elaborado.

El fenómeno es el aparecer inmediato, primario; el hecho va siendo merced a una mediación a una manipulación de dicho aparecer o aparentar. El hecho (factum en latín) deviene tal porque su proceso dinámico, frente al inmóvil camaleonismo del fenómeno, responde a la intervención de un factotum, esto es, un hechicero, un hacedor de hechos, ya sea el mago, ya el alquimista, ya el científico. Dicho factotum, si acata la Tradición - una sola desde los gnósticos de ayer a los laboratoristas de hoy- debe respetar el orden secuencial (observación, hipótesis, experimentación, teoría); los científicos geniales, fuera de serie, están más allá del orden y la tradición, tal cual lo revelan los a priori de Galileo y las intuiciones de Einstein ${ }^{16}$. La realidad de las cosas no es por lo tanto una especie de emanación de los fenómenos, como algunos sostienen: "para nuestro propósito bastará definir la realidad como una cualidad propia de los fenómenos que reconocemos como independientes de nuestra volición... ${ }^{17}$.

Tampoco la realidad de las cosas es un mero «reflejo» de la apariencia fenoménica en el cerebro humano - sensaciones y percepciones mediante- el cual vendría a operar como un speculum mundi, como una cámara fotográfica receptiva y pasiva. La realidad de la polución ambiental, por ejemplo, trasciende los fenómenos inmediatos de los efluentes industriales que afectan la salud humana, dañan los ecosistemas y degradan los paisajes. Del mismo modo la responsabilidad por esos perjuicios no es colectiva - «todos somos contaminadores; todos debemos pagar la descontaminación» - sino de los empresarios que, mediante personeros muy bien remunerados en los mass media, procuran aparecer ante la opinión pública como paladines del progreso y fabricantes cuidadosos. En definitiva, la realidad última de la contaminación como hecho objetivo y la responsabilidad por ella como hecho subjetivo se halla más allá del cuándo, del cómo y del quién circunstanciales para denunciar el porqué crematístico y el para qué socio-económico de los modos de producción (llamados hoy eufemísticamente «estilos de desarrollo») imperantes en el mundo industrial contemporáneo.

Para llegar a la esencia, al ser de la realidad, a veces hay que dinamitar $-y$ otras veces desmontar muy sutilmente- las vallas fabricadas por la astucia fenoménica que defiende y recata la intimidad de lo real. La médula de las cosas es inaccesible al mero repertorio sensible de la persona. El puro mirar óptico es distinto del ver intelectual. La mirada se detiene en la superficie de los objetos o los procesos y es asunto de política, aunque el término alarme a los que pactan con el statu quo, saber levantar las piedras para encontrar a los cangrejos bajo ellas escondidos, y verlos entonces a la inclemente luz de la verdad.

Fenómeno viene del griego phainomenon y significa lo que aparece, o aún lo que deslumbra y enceguece con su aparición y no deja ver detrás suyo, pues deriva de phos, photos, luz. Por lo tanto el fenómeno es el fogonazo, la manifestación luminosa de lo real, no lo real mismo.

Por atenerse al testimonio de los sentidos la astronomía helénica sistematizada por Aristóteles -tras quien se hallaba el poder de Alejandro Magno, no olvidarlo- desembocó en los 
empecinados planteamientos de Ptolomeo y sus epígonos medievales los cuales sostenían que la Tierra ocupaba, sin girar ni rotar, el centro del sistema planetario. La observación desprevenida e ingenua de los fenómenos, de las apariencias y no de los hechos reales prestidigitados por aquellas, proclamaba con argumentos emanados de la certeza descriptiva de los sentidos que el Sol y los demás planetas giraban en derredor de la Tierra, reina y señora de la creación, y que los cielos estrellados eran un brillante adorno de tachuelas claveteadas por Dios en el terciopelo de la noche (y de ahí el nombre de firmamento: lo que no está en perpetuo vagabundeo como los errantes (planetes); lo que permanece firme y no se mueve, porque la quietud es beatitud y plenitud).

Para explicar de un modo plausible las simples apariencias, Ptolomeo y su escuela convirtieron al Almagesto - «el más grande de los libros», en árabe- en un complejísimo tratado de trigonometría esférica basada en epiciclos, deferentes y ecuantas que, por no darle razón a los tempranos heliocentristas Filolao y Heráklides, embrolló con una falsa matemática y una atormentada geometría la sencilla realidad. El Almagesto, no obstante, procuró explicar racionalmente el sistema geocéntrico. Hoy también existen «explicaciones» parciales o globales de la realidad ambiental tales como las propuestas por los nietos de Malthus que achacan la creciente escasez de recursos al aumento veloz de la población y para conjurar sus peligros cortan epididimos y ligan trompas a los habitantes del Tercer Mundo. La realidad es que el $18 \%$ de la población mundial, que habita los países industrializados, consume el $84 \%$ de los recursos del planeta Tierra, pero los neomalthusianos no proponen castraciones en masa en los EE. UU. y Europa, tal cual las practican entre los campesinos colombianos. En su sistema etnocéntrico los países capitalistas industrializados se consideran el ombligo del mundo y los habitantes de la periferia, potenciales protagonistas de revoluciones liberadoras o rebeldías anárquicas, aparecen como los malos del cuento, como los devoradores de recursos, como los vándalos de los ecosistemas frágiles. Merced a este Almagesto social las relaciones Norte-Sur se entablan según la geoestrategia del imperialismo económico: las ecuantas, epiciclos y deferentes de la ideología aluden los fenómenos sin explicar las realidades, privilegian los medios pero ocultan los fines. De tal modo se apelan a las mismas argucias, ya que no argumentos, usadas por la Inquisición para sofocar con el fantasma de la herejía o el merodeo del Demonio la búsqueda científica de la verdad.

Volviendo a los griegos, cuyas ciencia y técnica estuvieron por debajo de su filosofía, puede señalarse la falsedad de otro razonamiento, basado en fenómenos incontrovertibles. En efecto, razonando con toda propiedad se dejaron engañar por la composición del núcleo metálico de los meteoritos ( $\mathrm{Ni}, \mathrm{fe}$ ) y por lo tanto llamaron sideral, o sea de hierro (sideros), al conjunto de los cuerpos celestes - Anaxágoras creía que el Sol era metálico - sin advertir que su inducción se hacía a partir de la fase final de un proceso. En efecto, el metal del núcleo aparece cuando las capas pétreas del «aerolito» han sido consumidas por la ignición durante, el razonamiento con la atmósfera. Por otra parte el universo es liviano, casi gaseoso, a tal punto que los átomos pesados constituyen el 1 por mil de la materia que forma los astros. No obstante éste y otros errores, surgidos de la información directa de los sentidos, los griegos supieron salvar las apariencias, es decir, salvar los fenómenos, para legitimar el orden del mundo. En la misma 
dirección, y mucho más tarde, Leibniz hablaría de los a posteriori de los sistemas construidos para salvar las apariencias y explicar modélicamente la realidad «tal cual es» y no tal cual se manifiesta.

Sin embargo, no es correcto oponer abruptamente el fenómeno a la esencia de la cosa. Entre ambos existe un diálogo advertido por Hersch al comparar el ser y la forma: «la presencia evidente se hace a la vez criterio de la realidad y de la no realidad». Dicho diálogo se convierte en dialéctica en Kosik a partir de su lectura epistemológica de Marx ${ }^{18}$.

Kosik procede con un admirable esprit de finesse. No es un dialéctico ortodoxo del marxismo vulgar, endiosado por múltiples generaciones de «filósofos oficiales» de Rusia. Kosik insiste una y otra vez, con reiteración casi fatigante, que el fenómeno muestra y oculta la esencia de la cosa al mismo tiempo. La esencia se manifiesta en parte en el fenómeno y en parte esconde su quidditas, aquello que es efectivamente. En verdad, la esencia no se revela de inmediato, súbitamente, como un relámpago: es mediatizada por el fenómeno y se manifiesta en algo distinto de lo que es. La esencia se insinúa de modo inadecuado y parcial en el fenómeno pero, al hacerlo, pese a las imperfecciones y gangas fenoménicas, a las reticencias y meandros, demuestra que no es pasiva. Del mismo modo el fenómeno revela la esencia. Pero levanta alguno de los velos, no todos. Y esa manifestación neblinosa, velada, de la esencia, constituye la actividad del fenómeno:

Si la esencia no se manifestase en absoluto en los fenómenos, el mundo de la realidad se distinguiría de modo radical y esencial del mundo fenoménico: en tal caso el mundo de la realidad sería para el hombre 'el otro mundo' (platonismo, cristianismo) y el único mundo al alcance del hombre sería el mundo de los fenómenos [...] En virtud de que la esencia -a diferencia de los fenómenos - no se manifiesta directamente, y por cuanto que el fundamento oculto de las cosas debe ser descubierto mediante una actividad especial, existen la ciencia y la filosofía. Si la apariencia fenoménica y la esencia de las cosas coincidieran totalmente la ciencia y la filosofía serían superfluas ${ }^{19}$.

\subsection{El medio humano}

Los ambientes donde transcurre la vida de las comunidades humanas son más complejos y simbólicamente más significativos que los estudiados por los ecólogos.

Los hombres, salvo las excepciones de algunas tribus ágrafas dedicadas exclusivamente a la recolección y a la caza, ya no viven inmersos en los ecosistemas locales. Los vegetales y los animales no saben manejar las energías extrabióticas ni poseen cualidades geúrgicas como para fabricar paisajes, salvo el caso de los castores y las termitas. Se ha calculado que el hombre antes de la domesticación del fuego consumía, per cápita y por día, $2.000 \mathrm{Kcal}$. Este consumo aumenta a 4.000 mil Kcal. cuando, a partir del sinanthropus pekinensis, hace medio millón de años, se incorpora el fuego a la vida humana; pasa a $12.000 \mathrm{Kcal}$. en las sociedades agropastoriles primitivas; llega a $24.000 \mathrm{Kcal}$. en las sociedades agrícolas hidráulicas 
-Egipto, Mesopotamia, Punjab, China del Hoang-Ho, andenerías incaicas, chinampas mexicanas, canales de la costa peruana-; salta a $70.000 \mathrm{Kcal}$. en las sociedades industriales de baja tecnología en la Europa de mediados del siglo XIX; y finalmente, en las sociedades industriales avanzadas de nuestros días - la de EE. UU. por ejemplo- alcanza la fantástica cifra de $230.000 \mathrm{Kcal}$.

No se ha advertido aún claramente, salvo algunos pocos investigadores - White ${ }^{20}$, Lilley ${ }^{21}$, Odum $^{22}$ - el papel fundamental desempeñado por la energía en el avance de la civilización y en la paralela degradación de los ambientes donde transcurre la vida humana. Odum, en tal sentido ha dicho con acierto:

La mayoría de la gente piensa que el hombre ha progresado en la moderna era industrial debido a que su conocimiento y su inventiva no tienen límites, lo cual no es más que una peligrosa verdad a medias. Todos los progresos se deben a subvenciones especiales de energía, evaporándose aquellos cuando se suprimen éstas. El conocimiento y la invención son los medios para aplicar los subsidios de energía cuando se dispone de ellos, y el desarrollo y conservación del conocimiento también dependen de la potencia desarrollada ${ }^{23}$.

Las grandes divisiones entre los países ricos industrializados y los países pobres esquilmados han sido enmascaradas de muchas formas y quienes las desenmascaran encuentran, en el meollo de la antinomia Norte-Sur, el quid energético:

El uso de la energía en el mundo está enormemente desequilibrado. El consumo de energía por cabeza en los países industrializados, comparado con el de los países medianos y bajos, está en la proporción 100.10:1. Un estadounidense usa tanta energía comercial como dos alemanes o australianos, tres suizos o japoneses, seis yugoslavos, nueve mexicanos y cubanos, 16 chinos, 19 malayos, 53 indios o indonesios, 109 srilankeses (cingaleses), 438 malienses ó 1.072 nepaleses. Todo el combustible usado por el Tercer Mundo para todos los fines es apenas más que la cantidad de gasolina que quema el Norte para mover sus automóviles ${ }^{24}$.

La realidad de los ambientes humanos es una realidad humanizada y humanizante. Quienes hablan de residuos inhumanos o desviaciones inhumanas en el componente personal o en las actitudes sociales de los pueblos no entienden lo que efectivamente es el hombre. Lo inhumano pertenece al juego ecológico de la naturaleza, a la frescura instintiva del animal, al reino sedentario de la planta. Es absolutamente humano que haya existido un Atila o que Maquiavelo haya escrito en la Historia de Florencia «a los hombres poderosos, o no hay que tocarlos, o cuando se les toca hay que matarlos». En la misma línea del poder, meta política de los gobernantes, se ordenan las hecatombes de Assurbanipal o el genocidio hitleriano. Pero es también humano pugnar para que cesen los desvalores e injusticias que aquejan a la humanidad; es humano el amor al semejante y el proyecto histórico de un mundo sin señores y sin esclavos, sin capitalismos despiadados al estilo U.S.A. y sin burocracias estólidas al estilo Ruso sin naciones que vivan en la más ostentosa riqueza a costa de la miseria de las otras naciones y sin ejércitos que amenacen con la extinción de nuestra especie. El bien y el mal son 
humanos, pues, y quienes opinan que la técnica es inhumana o deshumanizante no saben lo que dicen. La técnica pertenece al tecnosistema, una emanación del antroposistema, y ambos integran con el geosistema y el biosistema la complejidad de los ambientes.

Los reduccionismos en materia ambiental son peligrosos y falaces. Cuando se extrapola indiscriminadamente el modelo de ecosistema natural (y se habla del «ecosistema urbano» por ejemplo) proyectándolo sobre lo político, lo tecnológico y lo humano en general, se recurre a un criterio ecologizante que falsea la realidad de la cultura.

Al detenerse en el caso de la ciudad. La ciudad no es un ecosistema, como se dice tan a menudo. La ciudad es un sistema muy alejado de la naturaleza primicial y su artificialidad es evidente. Se trata de un sistema muy complejo, evolucionado, tecnificado, humanizado, declinado espacial y temporalmente por los dispositivos de la cultura. Mumford ha definido la ciudad teniendo en cuenta todos los ingredientes históricos, sociales y arquitectónicos que en ella se concitan y combinan. De tal modo, la ciudad es una colección relacionada de grupos primarios y asociaciones que persiguen propósitos determinados: los primeros, tales como la familia y el vecindario, existen en todas las comunidades, mientras que los segundos son especialmente característicos de la vida de las ciudades. Esos diversos grupos se mantienen a sí mismos mediante organizaciones económicas que tienen un carácter más o menos corporativo o que están reguladas públicamente; y todos ellos se albergan en estructuras permanentes dentro de una zona relativamente limitada. Los medios físicos esenciales en la existencia de la ciudad son la sede estable, el albergue duradero, las facilidades permanentes para reunirse, hacer intercambios y depositar artículos y productos; y el medio esencial es la división del trabajo que no sólo intensifica la vida económica sino también los procesos culturales.

La ciudad, por consiguiente, y en un sentido completo, es un plexo geográfico, una organización económica, un proceso institucional, un teatro de acción social y un símbolo estético de unidad colectiva. La ciudad se convierte así en el punto de concentración máxima del poderío y la cultura de una comunidad, corno el foco donde convergen los rayos luminosos de la vida humana para formar un haz más rico en significado social.

Además de ser el símbolo de una relación social integrada donde se erigen el templo, el mercado, el palacio de justicia y la academia del conocimiento, es la ciudad un producto de la tierra que se edifica sintetizando y solidificando cada una de las fases de la vida del campo y vive su rutina diaria gracias a la sangre regional que continuamente la irriga. Es también la ciudad un producto del tiempo, un molde donde la vida de los hombres se ha enfriado y coagulado dando forma permanente, mediante el arte, a momentos que de otro modo se hubieran desvanecido en lo viviente. El tiempo, hecho visible en la ciudad, choca con el tiempo y mediante los estilos arquitectónicos, refleja el carácter de las generaciones humanas.

El espacio, por su parte, vierte en la ciudad sus representaciones, fuerzas e influencias remotas que se funden con lo local creando conflictos y armonías de especial significado. Pero el espacio, como elemento sustantivo, se reorganiza además artísticamente en la ciudad merced a 
los límites periféricos y a la silueta de los edificios. Junto con el idioma, la ciudad es la obra de arte más grande de la persona.

Las sacudidas mecánicas del ambiente urbano producen resultados sociales y las necesidades sociales dan lugar a invenciones que señalan nuevos rumbos a industrias y gobiernos. La mente adquiere forma en la ciudad y, a su vez, las formas urbanas condicionan la mente. La ciudad, en definitiva, representa el máximo de posibilidades para humanizar el ambiente natural y naturalizar la herencia humana: da una forma temporal al primero y exterioriza en moldes colectivos permanentes la segunda ${ }^{25}$.

A Mumford le faltó el enfoque sistémico contemporáneo para que su persuasiva e intensa caracterización destacara los aflujos y la organización de los subsistemas en la trama urbana. Dicha tarea ha sido ya emprendida por los que la contemplan con ojos sistémicos y biologizantes, convirtiéndola, con evidente tergiversación de la realidad, en un organismo.

Así, entre muchos, razona Rosnay:

El crecimiento y las enfermedades de las ciudades, la multiplicidad de sus funciones, su comportamiento cotidiano, sugieren que la ciudad reacciona como un organismo viviente comunicado con un ambiente que modifica indirectamente y que a su vez lo modela. Al igual que un arrecife coralino, una colmena o un termitero, la ciudad es a un tiempo soporte y consecuencia de la actividad del organismo social que vive en su seno. Es particularmente difícil, si no imposible, disociar en todo organismo las diferencias entre la estructura y la función. Es por ello que no debe temerse la analogía entre una ciudad y un organismo viviente, a condición, naturalmente, de colocar esta expresión entre paréntesis ${ }^{26}$.

Pero los ecologistas no lo hacen, y hablan entonces del ecosistema urbano, señalando los balances energéticos del metabolismo de las ciudades y suponiendo que al medir el aflujo de energía fresca y el aflujo de energía degradada, de entropía, de contaminación, en suma, están caracterizando las funciones de un gran organismo. De tal modo una ciudad industrial de un millón de habitantes consume diariamente 2.000 toneladas de alimentos, 4.000 de combustibles y 630.000 de agua mientras que sus desechos «metabólicos» suman 500.000 toneladas de aguas usadas, 120 de partículas sólidas, 2.000 de basuras y desperdicios y 950 de contaminantes atmosféricos. Fuente de calor y trampa de calor, nido de bucles, reservorios y procesos reciclantes, la ciudad surge ante los constructores e intérpretes de sistemas como un complejo mucho menos metafórico que el pintado por Mumford pero en ningún momento resulta lícito el recurso de la organicidad o al vitalismo ecosistémico de que hacen gala.

De todos modos el hombre y sus obras, por complejas que ellas sean al punto que en un futuro próximo harán cierta la predicción de Heisenberg («la tecnología, proceso biológico en gran escala» determinará que muchos aparatos técnicos «pertenezcan tan ineludiblemente al hombre como la concha a la ostra y la tela a la araña») ${ }^{27}$, no están por fuera de la naturaleza. Son parte de una naturaleza que se piensa a sí misma y se transforma siguiendo los dictados de una mente racional y racionalizadora. El biotopo irá cediendo su sitio a un tecnotopo: la vida, 
antiguo y generalizado continente de técnicas discretas, será el contenido de una tecnología a escala planetaria. Pero, al margen del futuro previsible, el espacio ambiental perseverará en tanto que paisaje, una entidad compleja que es mucho más que un territorio, mucho más que un nicho biológico o cultural, o que ambas cosas a la vez, puesto que el paisaje constituye una encrucijada visible, significativa, corroborante, del medio humano.

Los paisajes o ambientes humanizados erigen sobre los fundamentos inorgánicos y orgánicos de los escenarios naturales los dispositivos de la cultura objetivada, las relaciones de producción materializadas en formas cuantificables y cualificables. Todo esto supone una organización sociocultural del habitat ${ }^{28}$, una planeación del espacio productivo y simbólico que se halla totalmente alejada de los ecosistemas.

Los paisajes son a la vez productos congelados, fosilizados, de antiguos y recientes modos de concebir las transacciones del hombre con el ambiente, y sistemas dinámicos, bisagras donde se articula el paso del presente al futuro, anfiteatros y escenarios de las concreciones del trabajo humano.

El paisaje registra sistémicamente las obras de la persona y ofrece, a los ojos que saben contemplarlo e interpretarlo, las claves didácticas para «leer» las relaciones de producción existentes entre los distintos estratos sociales, el potencial tecnológico de la cultura en él expresada y el flujo de la energía e información que los sustentan.

Pero el paisaje no es la única clave para descifrar el medio humano o el ambiente total. Pertenece a una familia de entidades ambientales complejas ordenadas por González Bernández ${ }^{29}$ que van desde el ansicht der Natur humboidtiano (1808) al gheograficheskaya sistema de Sochava (1963), pasando los conceptos de biosfera (Süss, 1875), biocenosis (Möbius, 1877), microcosmo (Forbes, 1887), landschaft o gheograficheskii (Berg, 1931), ecosistema (Tansley, 1935), gheograficheskaya obolochka -envoltura geográfica- (Grigoriev, 1937), biogheotsenoz - biogeocenosis-(Sukachev, 1940), uróchische fatsiya -complejo territorial natural- (Sólntsiev, 1947), landsystem (Christian, 1950). Todos estos conceptos cualitativos deben ser cruzados por los conjuntos espaciales (isoesquemas) de R. Brunet ${ }^{30}$, de carácter cuantitativo, que se ordenan así: 1 , zona, $10^{7} \mathrm{~km}^{2} ; 2$, dominio, $10^{6} \mathrm{~km}^{2} ; 3$, provincia, $10^{5} \mathrm{~km}^{2 ;} 4$, región, $10^{4} \mathrm{~km}^{2}$; 5, comarca, 500 a $1.000 \mathrm{~km}^{2}$; 6, distrito, 5 a $50 \mathrm{~km}^{2} ; 7$, parcela, 1 área a 1 hectárea.

Finalmente, W. Ewald ${ }^{31}$, ofrece una matriz de funciones y variables de interacción compleja cuyo simple aspecto mecánico resumo a continuación.

Ewald, al organizar esta matriz tuvo en cuenta la siguiente opinión de J. Bronowski:

La ciencia no es un conjunto de hechos sino una manera de conferir el orden, y a partir de allí dar unidad e inteligibilidad los hechos de la naturaleza. 
A los efectos de hacer inteligibles los ambientes concretos enumera las funciones y las variables pertinentes. Entre las funciones considera: 1) vida familiar; 2) escuela; 3) comercio; 4) transporte; 5) trabajo; 6) creación -en el sentido espiritual 7) ocio y recreación; 8) disfrute de la naturaleza; 9) asistencia a la enfermedad. Por su parte las variables controlables son: 1) clima; 2) aire; 3) agua; 4) materias sólidas de desecho; 5) ruido; 6) ingestiones suplementarias -alcohol, drogas -; 7) seguridad; 8) intimidad; 9) cantidad bruta; 10) densidad; 11) duración; 12) frecuencia. Estos cuatro últimos numerales «pueden referirse al tránsito, a la población, al ruido, a la vivienda». Una vez establecidas las funciones y las variables, Ewald pide auxilio al ingeniero $M$. Fiereing para que le confeccione tres matrices: la de variables controlables, la de funciones tecnológicas y la de intercambio (relación de las funciones entre sí).

Finalmente, echa a rodar estos filosofemas, a cual más contradictorio (como el que sigue), pues repudia las matemáticas para caer en brazos de la computación al cabo de un confuso disparatario:

Mientras que la enumeración de funciones variables parecía bastante simplista, ahora que las consideramos en relación con el medio ambiente humano pueden mostrarse como reducibles a una ecuación matemática. No es exactamente el caso. No tenemos la intención de reducir la realidad a una ecuación y dejar que los expertos determinen nuestro destino. Por el contrario, estamos en la búsqueda de una definición más precisa de la realidad. No debemos satisfacernos con una definición supersimplificada de las realidades del medio ambiente, simplemente porque esto sea todo lo que pueden asir nuestras mentes sin auxilio alguno. La mente humana es incapaz de seleccionar y relacionar las múltiples variables del medio ambiente y sus miríadas de combinaciones simultáneas. Pero la creación de ambientes realmente humanos a la escala en que lo estaremos haciendo en este país (U.S.A.) y en el mundo en el curso de los próximos cincuenta años, requiere necesariamente de esta información exacta. Se requiere la capacidad de las computadoras. La matriz es un medio de comunicación con la computadora ${ }^{32}$.

Hay mucho más que decir acerca del valor heurístico de los paisajes pero se debe pasar a otro tema. Antes de terminar señalo que a los efectos de la clasificación de los paisajes humanizados me remito al viejo estudio de Urabayen, cuya utilidad no ha utilidad no ha caducado ${ }^{33}$.

Las estructuras, las funciones y la evolución de los ambientes concretos, en cuanto que hechos y procesos reales, están enmascarados para el hombre común -y para la cotidianidad familiar o convivencial del hombre docto- por la aceptación tradicional de las apariencias, por el cumplimiento de los ritos ceremoniales (y ceremoniosos) del tú, del él y del nosotros. Por otra parte los aparatos del poder insisten en mostrar lo adjetivo o pintoresco de las relaciones sociales, en cegar con el brillo de los espejuelos de lo coyuntural. El gran todo y sus estructuras reales, el holon del sistema ambiental, que es en definitiva la clave política del medio humano, se maneja de tal modo por las fuerzas alienantes de la sociedad (fuerzas económicas, fuerzas confesionales, fuerzas administrativas, fuerzas culturales) que al final los árboles de la comarca no dejan ver el bosque de las estructuras regionales. La totalidad significativa del ambiente se 
fragmenta en mecanismos particulares (los de los intereses creados), en islotes de voliciones y referencias afectivas, en racimos de acontecimientos vividos al nivel del drama o de las comedias personales pero no comprendidos en tanto que eslabones de una cadena social.

La antropofanía de la vecindad, de la familiaridad con las cosas, llena de resonancias subjetivas la realidad ambiental e impide su verdadero conocimiento. Se contemplan las olas de la superficie pero no se capta el significado de las corrientes profundas: en definitiva, la dialéctica del fenómeno esconde la dialéctica de la esencia.

Tal es lo que sucede con el tratamiento ideológico de la contaminación. Las campañas oficiales y privadas para mantener limpias las ciudades le recuerdan a cada instante a sus habitantes que no se deben arrojar papeles en la calle, que las basuras deben ser guardadas en canecas malolientes (so pena de dañar el ambiente doméstico) en espera de los dos turnos semanales de su recolección municipal, que todos somos los responsables de la pulcritud de las aceras y las fachadas de las viviendas. Pero ese mismo municipio o esos diligentes particulares de las «sociedades protectoras de animales» y otras semejantes, nada hacen para que los automóviles - los escaparates del status - no contaminen con sus millones de motores de imperfecta carburación la atmósfera de los centros urbanos. Las autoridades protestan porque un niño bota una cáscara de fruta a la vía y nada disponen en contra de las urbanizaciones piratas llevadas a cabo por comerciantes -y políticos - prominentes que devoran las tierras productivas de los ejidos y exigen prolongaciones onerosas a los servicios de luz eléctrica y alcantarillado. Tampoco se escuchan las protestas oficiales cuando los grandes taladores de bosques dicen a grito pelado en los medios de comunicación que antes de echar la selva a tierra han sembrado, con solícito espíritu de respeto al ecosistema, los árboles que convertirán luego en pasta de papel. Estas mentiras son convertidas en verdades por el martilleo de la propaganda y admitidas sin sobresaltos por el común de las gentes.

En los ejemplos anteriores, unos pocos entre los tantos que podrían citarse, las apariencias externas encubren los mecanismos verdaderos, la representación oscurece el concepto, la falsa conciencia suplanta la conciencia real, y las nociones inmediatas manipuladas doctrinaria, ideológica o comercialmente impiden la comprensión mediata. De este modo los profesionales del ocultamiento despistan la opinión pública al tiempo que suprimen la capacidad crítica individual.

La realidad ambiental que rodea a la persona es, en definitiva, la realidad social, puesto que son sociales las organizaciones, las motivaciones y las manipulaciones que provocan y tergiversan la contaminación y degradación de los ambientes.

Al respecto resulta interesante trascribir dos agudos puntos de vista sobre la contaminación y su relación con la estructura de las sociedades humanas. Un autor alemán, luego de describir las condiciones de existencia de los obreros decimonónicos «un atentado contra la vida humana»agrega: 
Esta situación que podríamos ilustrar con muchos otros documentos del siglo XIX habría ofrecido ya la oportunidad de entregarse a reflexiones ecológicas a un 'observador neutral'; sólo que no existía ese observador. Nadie cayó en la cuenta de que aquellos hechos eran susceptibles de provocar conclusiones pesimistas acerca del futuro de la industrialización. El movimiento ecológico sólo ha surgido en el momento que los barrios residenciales burgueses y las relaciones vitales de la burguesía han sufrido el gravamen ambiental propio del proceso de industrialización. Lo que horroriza a sus profetas no es tanto el desastre ecológico, vigente desde tiempo inmemorial, cuanto su generalización ${ }^{34}$.

Por su parte, uno de los participantes en el Modelo Mundial Latinoamericano de la Fundación Bariloche ha escrito:

Algunas predicciones en boga (matemáticas o no) anuncian que si continúan las tendencias actuales de la humanidad se producirá una catástrofe mundial en un futuro no muy lejano. En realidad, la catástrofe contenida en esas predicciones constituye ya una experiencia cotidiana para gran parte de la humanidad. Hambre, analfabetismo, muerte prematura, etc. -en otra palabra, condiciones miserables de vida-conforman el destino común compartido por gran parte de los habitantes de los países subdesarrollados ${ }^{35}$.

Ante la inminencia de una crisis ambiental a escala mundial hay autores que comparan a la población de los EE. UU. Con los tripulantes de un bote salvavidas luego del naufragio. Los nadadores que bracean alrededor del bote - los habitantes del Tercer Mundo- piden subir a bordo. Pero ¿̇pueden subir todos? La respuesta es no: a la solidaridad humana se oponen factores de seguridad. Para que el bote no zozobre sólo algunos pocos privilegiados podrán subir. Los otros están condenados a la muerte ${ }^{36}$.

Los que así razonan, G. Hardin y J. Baden, estadounidenses ambos, piensan que el bote salvavidas estará ocupado por sus conciudadanos y sus aliados. Pero żsi sucede al revés? Si son los habitantes del Tercer Mundo los sobrevivientes a una catástrofe ambiental que tendrá también mucho de catástrofe nuclear, bacterial y química al mismo tiempo żpodrán subir a su balsa los remanentes del mundo industrializado? Sin ir tan lejos un ingeniero italiano, analizando la hipótesis de un colapso energético de New York en pleno invierno, vaticina que "José Gutiérrez, el portorriqueño», habitante del ghetto latino, sobrevivirá, mientras que los residentes en apartamentos de tecnología altamente sofisticada y centralizada perecerán ${ }^{37}$.

Los ejemplos anteriores, con ser pocos, sirven para demostrar que la realidad es una totalidad descifrable si se la interroga convenientemente. Dicha totalidad es cualitativa antes que cuantitativa: su inteligibilidad no se logra sumando hechos singulares cuya variedad es inabarcable y prácticamente infinita. En tal sentido podría decirse que la realidad es metafáctica pues constituye un sistema cuya lógica revela una legalidad global y englobante, situada más allá de los acontecimientos singulares que asaltan y extravían la razón. 
Logrando el desasimiento de la vida cotidiana - métodos y técnicas del pensar y del conocer mediante - es posible obtener una visión integradora y cualitativa de las cosas y «reemprender el viaje de retorno a las esencias». Así pertrechado el espíritu podrán removerse los escombros fragmentarios del diario vivir para interpretar las líneas maestras de la vida social cuyo desconocimiento provocaron la pasión romántica y la náusea existencialista, ambas intensamente reaccionarias. Quien proceda de este modo:

no tendrá esta vez la representación caótica de un conjunto sino una rica totalidad con múltiples determinaciones y relaciones ${ }^{38}$.

\subsection{Las circunferencias circunscritas del ambiente.}

Es muy frecuente emplear indistintamente los términos entorno, medio, medio ambiente y ambiente para designar las realidades que rodean a las comunidades humanas. Dichos términos no son sinónimos y se impone por lo tanto un deslinde semántico.

La primera confusión proviene de la mezcla de la terminología propia de las ciencias biológicas con la terminología de las ciencias sociales y humanas. Denunciando tal descuidada costumbre, consecuencia de inercias y préstamos semánticos, von Uexküll decía que el animal vive e interactúa en un ambiente (Umwelt) mientras que la persona construye y le da sentido a un mundo (Welt). El ambiente aparece así como un contorno natural y el mundo como un contorno cultural $^{39}$.

Sin embargo, no es correcto separar tan drásticamente el contorno del animal, el contorno de la persona. La persona, decía un antropólogo, no es ni un ángel caído ni un antropoide erguido. Su historia paleontológica y su historia mental conforman un diálogo entre el homínido y el humánido de tan intrincada urdimbre que los valores nicho ecológico y nicho cultural se determinan recíprocamente. La persona, ciertamente, tiene un organismo vinculado con el proceso evolutivo de todos los organismos vivientes: comparte con la ameba los mecanismos de los ácidos nucleicos que acuñan la información genética, con el faisán la calidad de vertebrado, con la vaca la condición de mamífero y con el chimpancé la especificidad de primate. Pero los animales no han establecido el celibato eclesiástico, ni recreado teatralmente la realidad como Sófocles, ni ayunado como protesta política, ni deformado el cráneo de sus hijos por motivos rituales o estéticos, ni practicado harakiri por razones de honor. Todos los intentos efectuados por los conductistas y los etólogos para persuadirnos que somos animales - según Ardrey ${ }^{40}$ del peor tipo depredatorio - revelan una peligrosa ideología al servicio de los traficantes de armas y los señores de la guerra. La imagen de la tolerancia forjada por la llustración (Locke, Voltaire) y las virtudes de la ayuda mutua exaltada por los anarquistas (Kropotkin, Rocker, Malatesta, Lorenzo, Read) es hoy subvertida: el hombre es un animal imperial ${ }^{41}$, es un animal cultural $^{42}$, tiene instintos y conducta de animal carnívoro ${ }^{43}$, desciende de los fabricantes de armas letales del África del Sur ${ }^{44}$. 
No es ahora el momento propicio para teorizar sobre el ser real de la persona, pero existen testimonios históricos que demuestran su temprana emancipación del puro reino de la necesidad y el azar. Los experimentos etológicos muestran el reverso de lo humano: la ratología, la pajarosofía, la perromanía y la simiografía de laboratorio o al natural sólo pueden servir para dibujar las configuraciones externas de la actividad animal y en última instancia para describir la fisiología a cielo abierto de la conducta ecológica ${ }^{45}$. Como dice un psicólogo, a los conductistas:

la persona cabal se les extravió entre reflejos condicionados y rutinas de corte gregario ${ }^{46}$.

La persona ha sido caracterizado como ser inteligente (homo sapiens) ser parlante (homo loquens), como ser que trabaja (homo faber), como ser que anticipa el futuro (homo prospector), como ser religioso y artístico (homo spiritualis), como ser conductor de objetos (homo artifex) y muchas otras cualidades más, solemnizadas por sus respectivos latinajos, tiene, no obstante sus escapatorias metafísicas o políticas, un profundo anclaje en lo somático, en lo fisiológico, en la «lógica de lo viviente» ${ }^{47}$.

Pero es, además, la única criatura que ha creado ambientes totalmente tecnificados, que ha establecido con otros hombres relaciones de producción y se ha estratificado en clases - nadie ha encontrado aún un gorila capitalista o un babuino perteneciente al lumpen proletariat-, que ha inventado mundos poéticos, que ha perseguido quimeras, que ha trascendido lo orgánico con la creatividad de su mente y la axiología de sus valores. Quedarse solamente en la conducta y borrar la conciencia y la cultura equivale a borrar la humanidad, con todo lo excelso y miserable que conlleva esta condición, nuestra condición, a mitad de camino entre la biosfera y la noosfera.

El ambiente de las personas organizadas en sociedades productoras y consumidoras de bienes y servicios - que la simplificación sistémica reduce a un input y un output abstractos - se despliega en el espacio y en el tiempo. Pero sus caracterizaciones, ya que los sentidos actúan aquí y ahora, se resuelven descriptivamente en la pura dimensión espacial: ámbito es espacio vital, panorama significativo, intinerario didáctico.

Las organizaciones y concepciones humanas del espacio constituyen la clave para comprender la estructura del ambiente. La persona vive en los espacios por él construidos; la arqueología del hábitat estudia el ayer y el anteayer de los paisajes culturales (y de aquí país, paisano, pagano); los paisajes, por su parte, son una modelización visible, materializada, de distintos estilos de concebir y practicar la convivencia humana. Puede descifrarse en los la historia de las civilizaciones que los construyeron y poblaron. Se puede también pensemos en un paisaje de Puerto Vallarta interpretar, sin ningún aparato discursivo, las relaciones de producción entabladas entre las sociedades que los habitan.

Los espacios de la persona económicos, geopolíticos, ambulatorios (desde el homo viator de los tiempos pedestres al viajero el jet set)- han sido analizados de modo muy diverso por los tratadistas y así tenemos poéticas del espacio, psicologías del espacio, proxemísticas, 
espaciologías y estudios colindantes, unos de tipo ensayístico, otros de tipo filosófico y científico. ${ }^{48}$

Cassirer hace una interesante clasificación -o tipificación- del espacio según sus relaciones con los biosistemas y los antroposistemas. En el caso de los animales Cassirer distingue entre espacios orgánicos y perceptivos. Los espacios orgánicos corresponden con los organismos más sencillos, que se adaptan al medio mediante tropismos, y los espacios perceptivos son propios de los organismos complejos, cuya adaptación al medio y el conocimiento del mismo son bastante más complicados pues sus sentidos captan y organizan el espacio circundante de tal modo que los investigadores pueden comprender pero no experimentar sus sistemas preceptúales. Pero en el caso de la persona:

Más bien que investigar el origen y el desarrollo del espacio perceptivo tenemos que analizar el espacio simbólico. Al abordar este tema nos encontramos en a frontera entre el mundo humano y el animal. Por lo que respecta al espacio orgánico, el espacio de la acción, el hombre parece en muchos respectos muy inferior a los animales. Un niño tiene que aprender muchas habilidades que el animal trae consigo; pero el hombre se halla compensado [...] por otro don que sólo él desarrolla [...] No de una manera inmediata sino mediante un proceso mental verdaderamente complejo y difícil llega a l a idea del espacio abstracto [...] que e abre paso [...] para una dirección completamente nueva de su vida cultural ${ }^{49}$.

Un autor que no provienen del campo filosófico sino del arquitectónico encara la multivalencia del espacio humano de otro modo. Desecha en primer lugar la consideración del espacio sintético de la persona primitiva, apreciado en ciertos aspectos al espacio unitario del niño estudiado por J. Piaget en múltiples libros. Sobre tal "persona primitiva" es lícito preguntas si es que verdaderamente hubo alguno de estos ejemplares al alcance de los etnógrafos o si sólo se trata de una construcción ( ¿̇o imaginación?) de los rousseaunianos -le bon sauvage -del siglo XVIII o de la Völkerkunde alemanda de fines del siglo XIX -los Naurvölker de Vierkandt -. La persona primitiva contemporánea no existe. Los llamados salvajes de (de selvagem, hombre de las selva en portugués, aún en el caso extremo de los recolectores y cazadores, - los ba-binga del Africa ecuatorial, los arunta australianos, los extinguidos yámanas de Tierra del Fuego-ya están muy lejos de los neandertales.

Si bien su cultura material es poco significativa el sistema de parentesco australiano es más complicado que el nuestro y tanto yámanas como negrillos congoleses conciben un Dios único, dispensador de castigos y recompensas, creador de la vida y la Tierra, muy semejante al Dios judeocristiano. En cuanto al hombre "civilizado", éste maneja seis conceptos de espacio:

Hasta ahora hemos distinguido cinco conceptos de espacio: el espacio pragmático de la acción física, el espacio perceptivo de orientación inmediata, el espacio existencial que forma para el hombre la imagen estable de ambiente que le rodea, el espacio congnoscitivo del mundo físico y el espacio abstracto de las puras relaciones lógicas. El espacio pragmático integra al hombre con su ambiente orgánico natural; el espacio perceptivo es esencial para su identidad como persona; el espacio existencial le hace pertenecer a una totalidad social y cultural; el espacio 
cognoscitivo significa que es capaz de pensar acerca del espacio, y el espacio lógico (abstracto) ofrece finalmente el instrumento para describir a los otros. Esta serie muestra una abstracción creciente desde el espacio pragmático que ocupa el nivel más bajo hasta el espacio lógico, que está en la cumbre, 0 , lo que es lo mismo, un contenido de creciente información. Cibernéticamente, pues, la serie es controlada desde la cúspide, en tanto que su energía vital surge desde el fondo. Sin embargo se ha omitido un aspecto básico. Desde tiempos remotos [...] también se ha creado espacio. A esta creación podemos llamarla espacio expresivo o artístico 50

A esta altura de la exposición se esta en condiciones de ordenar y clasificar la multiplicidad de espacios significativos que declinan a las sociedades humanas concretas y a la vez son producidos por ellas. La producción del espacio, estudiada por Lefébvre ${ }^{51}$, corre parejas con la utilización antrópica del espacio y tienes distintos acentos en las culturas maquinistas y no maquinistas, sagradas y profanas, monumentalistas e intimistas, etc. Entre un jardín japonés y el espacio imperial napoleónico, fácilmente inidentificable en París, cabe una gama de matices topológicos cuyo análisis ha sido ya emprendido por urbanistas, antropólogos y geógrafos: espacios privados, públicos, deportivos, religiosos, recreativos, políticos, etc.

Pero se va a operar en un plano más abstracto y a la vez más sistémico. Interesa por lo tanto una conceptualización progresiva y combinatoria que defina y relacione los contenidos y significaciones de cuatro términos concurrentes pero no semejantes: entorno, medio, ambiente y mundo. Se va a analizar por separado para proponer luego una teoría general del ambiente como totalidad y como sistema.

El entorno es el más amplio, genérico y neutral de los círculos concéntricos del espacio humano. Es el puro ámbito, la espaciosidad donde se alojan los seres y las cosas en cuanto que tales. El contorno configura el marco del entorno: coincide con el horizonte, con los últimos límites de lo visible. El entorno es el más amplio, genérico y neutral de los círculos concéntricos del espacio humano. Es el puro ámbito, la espaciosidad donde se alojan los seres y las cosas en cuanto que tales. El contorno configura el marco del entorno: coincide con el horizonte, con los últimos límites de lo visible. El entorno es el reino óptico de lo posible: del caminar hacia las lejanías, del abrirse a los paisajes y a al potencial plenitud de los mismos. El entorno constituye un telón de fondo que identifica la familiaridad de lo no usado pero siempre presente en cada amanecer: la cabalidad de las cosas, la buena fe del lo permanente, el orden de lo extenso. Tiene así el carácter de una mediatez sobre la cual cobra sentido el diálogo con lo inmediato. El estar ahí a la vista heideggeriano distingue dicha lejanía no requerida pero disponible cuya presencia remota nos sitúa en la habitualidad de los lugares y parajes a la par que ahonda hasta el horizonte sensible los sitios referenciales de la espaciosidad.

Acerca de esta espaciosidad del entorno los planteamientos de Zubiri, resumidos por Ellacuría ${ }^{52}$, tienen total pertinencia con lo que venimos desarrollando. 
El entorno de la persona es, de alguna manera, una réplica antropotécnica, a la escala de los paisajes visibles, del propio universo físico. En este mundo físico -debemos fisicalizar la presencia del hombre en cuanto que cuerpo visible, que concreción material usía praxis reproduce la materia- la realidad como ámbito viene a ser el principio, no de construcción sino de libre movilidad. El universo tiene el ámbito de un posible cambio respectivo dentro de ella porque el universo no está en el espacio sino que lleva dentro de sí el espacio. Trasladando esta característica del universo físico total a la escala del género humano - he aquí otro espacio referencial, el escalar, ejemplificado particularmente por las cartas y mapas geográficos o topológicos -podemos establecer que la espaciosidad de la realidad física que nos circunda consiste entonces:

No en ser principio de localización de las cosas que hay dentro de él, sino en ser principio del libre cambio respectivo, en ser ámbito. Principio en sentido estructural y no necesariamente causal ${ }^{52}$.

El ámbito viene a ser así una de las notas principales, si no la principal, del entorno.

El ámbito es principio de espacio como ámbito de una libre movilidad", entendiendo el movimiento como un cambio respectivo de un cuerpo respecto de otro. El ámbito es principio estructuradle que pueda haber movimiento respectivo; no es algo espacial sino pre-espacial, es lo que hace posible que haya espaciado ${ }^{53}$.

El ámbito, el entorno, el contorno, el dintorno, la circundancia, supone, pues, una mera espaciosidad. Ambito y espacio son dos momentos distintos de un proceso o, mejor, las caras de un ente abstracto:

El espacio no es el ámbito, sino la estructura métrica de los movimientos que en él se producen. Para que haya espacio es necesario "recorrer" el ámbito, de la misma manera que para que haya distancia no basta la longitud, sino que hay que recorrer la longitud. Si no hubiera la posibilidad de un movimiento que llevara de un punto a otro, no habría distancia sino mera diversidad de dos puntos que nada tienen que ver entre sí. La distancia es la manera como un punto tiene que ver con otro, y esta manera es que del uno al otro se pueda ir en un libre movimiento ${ }^{54}$.

El entorno, empero, no es invariable. El entorno sigue al hombre en su desplazamiento por la superficie del globo, como la sombra al cuerpo. La alegoría de von Chamizo sobre la persona que perdió su sombra puede trasladarse a la imaginación, más terrorífica aún, de la persona que al perder el contorno familiar pierda toda referencia y quede flotando, como una nudillo viviente, en medio de un entorno innominado - la persona de las cosas concede identidad a las cosas - sin orientación, sin referencia, víctimas de un naufragio espacial absoluto. Algo de esto sucede con quien se encara con nuevo horizontes: el etnocentrismo no es otra cosa que el llevar a cuestas, como el feréoikos, el caracol de Anacreonte, los paisajes maternos, los bártulos de un entorno familiar que se proyecta sobre los perfiles inéditos de lo desconocido y al quererlo legalizar lo tergiversan. 
Pero además el entorno incita a la aventura, provoca conquistar su lejanía y una vez conquistada ofrece a la vista ya la curiosidad del viandante, del conquistador, la convocatoria de otro entorno: así surge el plus ultra, el siempre más allá de la wanderung humana.

El entorno es, además, el arriba y el abajo. Son entorno la nube lejana y el juego de las constelaciones en el cielo nocturno; son entorno la mina de carbón y la soterrada fuente geotérmica. Se convertirán en medios cuando el hombre aproveche con sus molinos la fuerza del viento, o adopte con Franklin la electricidad a la nube, o cuando las naves espaciales y vuelen como abejas audaces en derredor de la colmena terrestre, si el camino es hacia lo alto; o cuando el minero británico el ingeniero de Larderello nos permitan acceder a las energías represadas en las profundidades, si el camino es hacia el interior de la litosfera. Medios también serán las potencialidades del horizonte cuando la praxis humana se sierva de ellas; es decir, cuando la potencia se convierta en acto.

El entorno percibido en tanto que ámbito capaz de recibir el movimiento de la vida, en tanto que horizonte y verticalidad de posibilidades, constituye un Merkwelt. Aquella parte del entorno que el ser viviente utiliza, o sea el ámbito actuado e incorporado, el ámbito que sustenta la vida, el medio propiamente dicho, constituye el Wirkwell ${ }^{55}$.

El medio adquiere aquí un significado concreto. El aire es un medio cuando yo lo respiro y posibilita mi existencia; el agua es un medio cuando yo la bebo, o viajo en un barco; la tierra es un medio cuando la cultivo, cuando sobre ella edifico mi casa y bajo ella tiendo una red de saneamiento. El medio del árbol, aprisionado con sus raíces en un espacio donde la geología y el clima lo impulsan hacia un climax de equilibrio -comunidad biótica y tiempo son los otros parámetros siempre presentes-s permanente. El medio de una ave migratoria que busca, en sus largos viajes del hemisferio norte al hemisferio sur y viceversa, condiciones propias para suavidad y la descendencia, tiene características muy distintas: el desplazamiento del grupo animal tras los lugares favorables para su alimentación y reproducción implica una búsqueda dinámica del medio, un juego espacial ausente en la planta. La dialéctica del árbol se expresa en la verticalidad; la del ave migratoria en el desplazamiento horizontal, en la peripecia del viaje.

Pero el medio de la persona supone otros elementos, otras nociones del espacio, otras duraciones del tiempo. Es un medio en el cual la condición humana ha puesto acentos tales de originalidad y mutabilidad que la estructura y la función del a naturaleza, esto es, la presencia del ecosistema, han sido sobrepasadas por la maquinaria cultural de la historia. El medio humano tiene, es cierto, un umbral primario que no puede desconocerse:

Entendemos por medio aquel subconjunto de cosas que dentro del conjunto que hemos llamado entorno puede servirnos para unos determinados objetivos o fines. Sólo entonces las cosas que nos rodean adquieren carácter medial, es decir, se convierten en medio de vida. Sin entrono no habría medio. Pero no todas las cosas 'a la vista' (entorno) están 'a la mano ' (medio). 
Podríamos estar rodeados de cosas y carecer de medios de vida, por ejemplo en un desierto [...] Podría decirse que el medio lo constituye el plexo o la totalidad circundante de útiles. Un útil es un algo para [...] conviene aclarar que 'útil ' no es sinónimo de "utensilio" [...] utensilio es lo manejable o manipulable, lo estrictamente a la mano, mientras que útil es lo disponible ${ }^{56}$.

Pero en el medio humano cuentan no ya los simples útiles sino las constelaciones significativas de artefactos y mentefactos, los soportes materiales y sociales de la cultura. El hombre nace en un tipo de sociedad muy distinto al de la planta y el animal. La hazaña de la civilización humana ha consistido en la apropiación y transformación de un entorno, siempre en retroceso, convirtiéndolo así en un conjunto de medios de vida basados en al producción. El ecosistema usa lo dado; el hombre, más allá de la química del vegetal y el fagotrofismo de la bestia, crea un medio simbólico en el cual los alimentos del espíritu cuentan tanto como los del cuerpo.

El animal no trabaja. La persona, mediante el trabajo, le dio sentido a la naturaleza que era un contorno abstracto, un escenario indeferenciado. Sobre el pedestal de la piedra y la madera, del hueso y del metal nativo, levantó el edificio de las distintas culturas aplicando técnicas para modelar la materia, para interpretar su residencia en la tierra, para proyectar los mundos futuros.

Las técnicas se convirtieron en tecnologías en el seno de los distintos modos de producción y la sujeción de unas vidas al imperio de otras, en estilo de vida; las tecnologías modificaron la faz del planeta y conformaron sociedades más complejas, más recursivas y a la vez más conflictivas que las comunidades puramente naturales. El símbolo arbitrario, el nomos, se erigió en la norma de la humanidad, y todo medio humano estuvo, desde la aurora de la cultura, condicionado por la costumbre moral y la moda intelectual, por el presente extrapolado hacia el futuro y por la selectividad ideológica de la radiación. El ecosistema se resuelve en el absoluto subsistir; en las sociedades humanas, además, se discute el convivir y se pregunta por el consistir. En el ámbito de las biocenosis la actividad vital genera en torno una entropía moderada; en el medio humano la actividad creadora grava los medios de la naturaleza con efluentes poderosos, saquea los recursos naturales, se ahoga en sus propios desechos. El colonialismo, antecedente y secuela del capitalismo industrial, constituyó uno de los más decisivos factores de la doble destrucción del medio natural y el medio humano en los territorios conquistados. El ecosistema en sí, en su pura naturaleza, no padece este tipo de servicios. La autorregulación interior y el diálogo con los espacios exteriores lo flexibilizan y conservan a lo largo de una asíntota de invariable eficacia. El antroposistema está afectado por intereses extrabiológicos: el afán de lucro, la ebriedad del poder, a actitud cáustica ante la naturaleza, que d madre sagrada pasó a ser botín profano, han planteado una serie de desafíos ubicados en otro terreno que el de la adaptabilidad de la vida al medio o a los medios circundantes.

De la potencialidad del entorno surge la utilidad de los medios y de la organización sistémica de los medios se generan los ambientes. El medio es, en verdad, una noción simplificador ay abstracta; la realidad ofrece por doquier distintos ambientes, distintos sistemas de medios. En algunos ambientes predominan los factores naturales y los antropoténcos están reducidos a expresiones mínimas: las malocas de las tribus amazónicas y los pequeños poblados de los 
frentes pioneros, donde la civilización se implanta insularmente en medio de la selva, son ejemplos válidos en tal sentido. En otros ambientes, de carácter casi exclusivamente tecnógeno, el medio natural ha sido prácticamente sustituido por las máquinas y los dispositivos de la cultura objetivada. Pero en ambos casos el ambiente es un sistema complejo, espacial y temporal a la vez, humanizado siempre. Hoy día todavía subsisten en tanto que antiecumene una parte de la Antártida, las cumbres de las altas montañas y ciertos lugres disérticos. La actividad humana ha cubierto la Tierra con sus obras y sus rutas, sus asentamientos y sus trampolines para ceder a las áreas poco conocidas o totalmente desconocidas. En pocos años más la tierra será acondicionada como un habitáculo total, como un hogar sin rincones inaccesibles o misteriosos, aunque todavía no sea una "patria para todos", pues la larga marcha por la justicia y la igualdad aún no habrá finalizado (si es que alguna vez finaliza).

En la actualidad aquellas tradicionales catapultas enfiladas hacia la aventura impulsan a la persona a nuevas empresas. No se trata ya de ir a buscar al Dr. Livingstone al corazón ecuatorial del Africa sino de salir a la conquista del espacio planetario y del espacio intragaláctico. Se van a generar así nuevos ambientes y es posible que la Luna y Marte sean, dentro de pocos decenios, escenarios de una humanidad que implante, mediante cápsulas presurizadas primero y la creación de atmósferas planetarias y ecosistemas locales después, sus estilos de ser y de hacer en los desiertos del cosmos.

El ambiente de la planta y del animal es un continuo hilobiopsíquico, según los distintos niveles de organización y según la frontera que se establezca entre tropismo y psiquismo. Visto desde el sujeto científico ese continuo se refleja en otro: el de la legalidad fisioquimiobiopsicológica. El ambiente de las sociedades humana es un sistema sin parangon. Más allá y más arriba del puro psiquismo se encuentran las relaciones sociales de producción, las superestructuras mentales, las mesoestructuras políticas, y, rodeando y condicionando lo demás, el universo tecnúrgico, las ergologías creadores, la sinergia del maquinismo.

En los ambientes humanos se integran con distintos tonos -el de las culturas- y distintos tempos los de la industrialización- el subsistema geocósmico, el subsistema bioecológico y el subsistema antrópico, íntimamente vinculado al subsistema tecnárquico ${ }^{57}$.

El ambiente humano, en definitiva, no es mas ecosistema, y de allí la posibilidad latente del código parcial o total; es, sobre todas las cosas, sociedad civil consumada y proyecto de una nueva sociedad, pacto con el establecimiento y ruptura con la tradición, anclaje en el pasado y salto hacia el porvenir, y de aquí derivan -a partir de la lucha de los opuestos, de las seducciones del poder- los peligros del genocidio, la espada de Damocles que a todos nos amenaza.

Entornos, medios y ambientes, si bien con diferencias genéricas, son compartidos por los seres vivientes y la persona. Pero hay algo que le confiere al ambiente algo específico e intransferible, propio del hombre. Se trata de la existencia de una realidad a horcajadas entre las presenciad e las cosas y la convivencia con las personas: el -estar-en-el-mundo. La norma de la cultura y el 
psiquismo de la personalidad confluyen en este especialísimo modo de ser y de sentir del género humano, orientado hacia la creación de mundos personales y sociales.

Mi mundo, nuestro mundo, poco o nada tienen que ver con el sentido cosmológico totalizador del término, o con los mundos fragmentarios de este planeta o con las disciplinas físicas, morales e intelectuales: el orden del mundo, el viejo Mundo, el mundo el deporte, el mundo del arte, el mundo de los hippies, el mundo del sexo, el mundo de los ciegos, el mundo del crimen, el mundo de la química, etc.

El concepto de mundo es existencial, vivencial, convivial. En la intimidad de la persona humana la experiencia de ambientes, seres y cosas ha dibujado un mapa moral, una serie de referencias afectivas, un programa vital para las transacciones con el Otro, con la alteridad objetiva o subjetiva. Cuando Stefan Zweig y su mujer se suicidaron en el Brasil, luego de un cálido crecimiento correspondido por el escritor judío con un bello y quizás excesivo libro, en la carta dejada por ambos se decía que habían perdido "su mundo". La Tierra persistía, Brasil era bello y acogedor, pero ya se habían cerrado las puertas hacia los dorados corredores del ayer: amistades con raíces eh el humus de una cultura compartida; sistemas de señales internalizados y por ello implícitos; alegrías y miedos colectivos ante vicisitudes políticas que convertían la crónica en historia. Ese mundo estaba perdido y ya jamás sería recuperado: ¿̇para qué vivir entonces si la mera duración zoológica no podía compensar el naufragio de los más valiosos bienes del alma?

Esta cosecha de mundos personales, brotados de los ambientes mundanos y mundanales -portadores de otra escala de valores que aquéllos - descarta el concepto idealista que afirma la existencia dela realidad a partir del sujeto. Sin embargo, ni las cosas, ni el sistema de las cosas, ni las comunidades humanas que nos rodean necesitan del yo personal para existir por sí y para sí, para recibir su ser o el sentido de su ser. Por eso yerra Sartre cuando dice que el hombre determina con su aparición la existencia de un mundo ${ }^{58}$ y Merleau-Ponty cae en un grave solipsismo cuando afirma "yo soy quien hace al mudo" ${ }^{59}$. El mundo cósmico, el mundo que no es ni voluntad ni representación sino realidad planetaria de la materia informada por la energía, no requiere la presencia de nuestra mano para tener relieve ni de nuestra vista para ordenarse en el espacio. El mundo es ya otra cosa: se trata de un microcosmos individual que configura la continuidad de nuestras vivencias en el tempo y de nuestras relaciones significativas con el ambiente. En el mundo la subjetividad psíquica y la estructura fisiológica determinan una cierta selectividad, un peculiar registro, unas especiales discontinuidades pautadas por lo afectiva y lo ideativo. Tales caracteres individuales se definen a partir de nuestro personal comercio con las personas y con a las cosas. Somos de ese modo el punto de encuentro entre el mundus sensibilis y el mundus inteligilis: los sentidos diseñan, como el sonar, los perfiles de la res extensa den las profundidades del océano de la materia; el razonamiento, la afectividad y la voluntad construyen, a partir de diversos e incompletos fragmentos el todo, de l a Realidad global, del Ambiente holístico, el edificio de la inteligiblidad, el puente humano de la palabra, la necesaria abstracción del concepto. El mundo resultante, en tanto que realidad ordenada y esquema ordenador, viene a ser así un constructor biográfico, un compromiso entre el pathos y el logos; 
encarna, en suma, el significado trascendente que tiene la persona en tanto que testimonio focal de la sociedad e interlocutora histórica de la naturaleza hogares alternos y complementarios de la inmanencia.

Contemplado desde esta perspectiva la persona, en tanto que humánido, traspasa los umbrales de los entornos y medios que lo condicionan en tanto que homínido; va mucho más allá de los sistemas ambientales que conservan su carácter de instrumentalidad y operatividad bióticas. La persona es tal, óntica y culturalmente considerado, a partir de su pregunta por la esencia de lo real, por la totalidad significativa de su escenario y por la razón de sus obras.

Los ecosistemas se resuelven y expresan en el absoluto presente; el homo prospector proyecta su mundo al porvenir o reclama otro mundo para sí y los suyos en la esperada consumación del Milenio y si el quiliasmo no funciona -como tal parece- lo prefigura mediante propuestas de convivencia (no importa si mejores, lo valioso es que sean distintas a las actuales) modelizadas en manifiestos políticos, económicos, artísticos, etc. En definitiva, el mundo de la persona es el habitáculo de los valores, el taller de la civilización. Y civilización es, aquello que nos aleja más y más de la animalidad.

Entorno, medio, ambiente, mundo: por estos círculos, concéntricos o excéntricos, transita desde sus orígenes la humanidad en búsqueda de signos que haga inteligible su misión planetaria de especie dominante. Hoy, exigiendo calidad del ambiente, se exige calidad de la vida; pero son grupos privilegiados, élites en suma, quienes, ya asegurada la factibilidad de la vida, aspiran a tener aire puro, agua abundante y limpieza, ausencia de ruido, ciudades a la escala del júbilo, paisajes amenos, recursos abundantes.

En el Tercer Mundo así como en los bolsones de pobreza y marginalidad del mundo industrializado, la lucha es distinta: se trata de vivir en vez de durar, de tener acceso a los bienes terrenales del hombre, acaparados por minorías del poder y el saber. Como muy bien ha expresado Marcuse:

La insistencia en estos valores, en restaurar la Tierra como medio ambiente humano, es no sólo una idea romántica, estética, poética, que concierne solamente a los privilegiados: hoy es cuestión de supervivencia. Preciso es que los hombres aprendan por sí mismos que es indispensable cambiar el modelo de producción y consumo, abandonar la fabricación de elementos bélicos, de cosas superfluas, de artefactos vanos, y reemplazar todo ello por la producción de objetos y servicios necesarios para una vida de trabajo creador [...].

La meta sigue siendo el bienestar, pero un bienestar no definido por un consumo mayor a costa de un trabajo cada vez más intensivo, sino por la conquista de una vida liberada del temor, de la esclavitud respecto del salario, de la violencia, del bullicio infernal de nuestro mundo industrial capitalista. No es cosa de embellecer lo abominable, de ocultar la miseria, de desodorizar el hedor, de enflorar las cárceles, los bancos, las fábricas: no se trata de purificar la sociedad actual sino de sustituirla ${ }^{60}$. 
Conviene señalar que si bien la realidad total tienen un radio mucho mayor que el del ambiente es posible afirmar que las realidades concernientes a los grupos locales del género humano se hallan en el ambiente concreto donde aquellos trabajan, producen y se reproducen.

La persona, productor de su propia vida, portador de su mundo personal y constructor, en asociación con otras personas, de ambientes, de medios humanizados, no puede evadirse al ritmo dialéctico de la alteridad. Desde la aurora del homo habilis hasta los presentes días del homo industrialis la sociedad humana ha intervenido, modificado y en ocasiones sustituido totalmente a la naturaleza, que hoy se ha dado en llamar, indiscriminadamente, ecosistema. Los ambientes antropógenos influyen a su vez en los caracteres somáticos, fisiológicos, psíquicos y culturales de las sociedades humanas. Las personas construyen los paisajes y los paisajes construyen y acondicionan la descendencia. La dialéctica histórica entre sociedades economizantes y ambientes así como la fabricación de medios simbólicos de adquiescencia colectiva, imprimen a las infraestructuras y superestructuras de la humanidad un vaivén protagónico en los juegos adaptativos y creativos que se han alternado a lo largo de su evolución. Los sistemas sociales y los sistemas ambientales no se pueden estudiar separadamente: son totalidades significativas que se imbrican y condicionan recíprocamente a tal punto que resulta difícil separar lo natural de lo artificial y viceversa.

Todo ambiente donde discurre la vida humana es un ambiente influye en la humanidad y la gran transformación futura de la vida social, cuando salgamos de la prehistoria en la que aún nos anclan la violencia clasista, el poder estatal, la rémora de los ejércitos y la desmesura etnocéntrica, modelará ambientes a la medida de una escala de valores más racionales que la actual.

S. Murgel Branco, (2000) Ecología, CETESB, Sáo Paulo.

${ }^{2}$ G. L. Clarke, (2001) Elements of Ecology, J. Wiley \& Sons, New York.

${ }^{3}$ ld. Ibid.

${ }^{4}$ A. Turk, J. Turk, J. T. Wittes, R. Wittes, (2002) Environmental Science, Saunders, Philadelphia.

5.W. D. Billings, (2002) Plants and the Ecossytem, Wadsworth Publishing Co., Belmont, (Ca.).

${ }^{6}$ M. J. Hersocvits, (2001) Man and his works. The science of cultural anthropology, A. Knopf, New York.

7.P. George, L'environment, (1999) Presses Universitaires de France, Paris. 
${ }^{8}$ O. Sunkel, La interacción entre los estilos de desarrollo y el medio ambiente en la América Latina, in O, Sunkel y N. Gligo, Op. Cit., T. Lo.

9.S. Hesselgren, (2000) Man's perception of man-made environment, Studentlitteratur, Lund (sverige).

${ }^{10}$ G. c. Gallopin. (1999) El medio ambiente humano, in O. Sunkel y N. Gligo Estilos de desarrollo y medio ambiente en la América Latina. Fondo de Cultura Económica. T. 10, pp. 205235.

11.El Kosmos, en tanto que "una comunidad jurídica de las cosas" es estudiando en los antiguos filósofos griegos -los siempre actuales presocrátcos, que en su momento histórico intelectual prothohistórica- por W. Jaeger, Paideia, Fondo de Cultura Económica, México, 1942-1945 y particularmente por R. Mondolfo, En los orígenes de la filosofía de la cultura, Hachette, Buenos Aires, 1960. Acerca del nacimiento de la polis y del pensamiento racional tiene muy interesantes planteamientos J. P. Vernant, Les orgines de la pensée grecque, Presses Universtiaires de France, Paris, 1998.

12.J. D. Bernal, (2001) The extension of man. The history of physics before the Modern Age, Weidenfeid and Nicholson, Londo.

${ }^{13}$ W. Kula, (2000) Las medidas y los hombres, Siglo XXI, México,

14.E. T. may, (2000) The Hidden Dimension, Doubleday \& Co., Garden City, (N. Y.).

${ }^{15}$ K. Ortega y Gasset, (2001) En torno a Galileo, Revista de Occidente, Madrid.

16.P. K. Feyerabend, (1998) Against Meted: Outline on an anarchistic theory of Knowledge, University of Minessota Press, Minneapolis.

17.P. Berger, Th. Luckmann, (1998) La construcción social de la realidad, Amorrortu, Buenos Aires.

${ }^{18}$ K. Kosik, (1998) Dialéctica de lo concreto, Estudio sobre los problemas del hombre y el mundo, Grijalbo, México.

19. Id. Ibid.

20.L. White, (2000) The science of culture, Grove Press, New York.

21. S. Lilley, Men, (2001) Machines and History, Lawrence and Wishhart, London.

22.H. T. Odum, (2002) Environment, power and society, J. Wiley \& Sons, New York, 
${ }^{23}$ Id. Ibid.

24. Comisión Willy Brandt, (1999) Norte Sur. Un programa para la supervivencia, Editorial Pluma, Bogotá.

25. L. Mumford, (2000) The culture of Cities, Harcourt, Brace \& World, New York.

${ }^{26}$ Id. Ibid.

27.W. Heisenberg, (2001) Das Naturbild der heutigen Physik, Rowohlt Verlag, Hamburg.

28.El concepto de habitat es polivalente. Para los arquitectos es la vivienda, pura y simplemente. Para los geógrafos es el espacio donde se asienta una comunidad humana. Los biólogos convierten el hábitat en el territorio donde vive una población; el concepto de nicho ecológico es distintos (habitat=domicilio; nicho= profesión). Finalmente la escuela de geógrafos humanos franceses considera, a partir de A. Demangeon, Problémes de Géographie Humanie, A. Colin, Paris, 2000, que el habitat está constituido por el asentamiento humano y el espacio económico circundante vinculado con aquél.

29.F. González Bernárdez, (1998) Ecología y paisaje, Blume Ediciones, Madrid.

30. O. Dollfus, (1998) L’espace géographique, Presses Universitaires de France, París.

${ }^{31}$ W. E: Ewald, Jr. (comp.) (2000) Environment for man. The next fifty years, Indiana University Press, Bloomington.

32. Id. Ibid.

${ }^{33}$ L. Urubayen, (2001) La Tierra humanizada. Geografía de los paisajes humanizados y la lucha del hombre por la conquista de la Naturaleza, Espasa-Calpe, Madrid.

34.H. M. Enzesberger, (2002) Zur Kritik der politishen Ökologie KursbuchRotbuch Verlag, Berlin.

35. A. Herrera, (2003) Modelo mundial latinoamericano, en Nueva Sociedad, no. 22, pp. 16-29, Caracas.

36. G. Hardin; J. Baden (ed.), (2000) Managing the Commons. W. H. Freeman, San Francisco, 2000. Incluye el etnocéntrico ensayo Living on a Libefoat del primero de los compiladores. El propio Hardin tiene un libro dedicado totalmente al examen de la moral de los poderosos en caso de un colapso mundial, cuyas ideas reiteran el planteamiento de 1999. The Limits of Altruism: an ecologist's view of survival, Indiana University Press, Bloomington. 
${ }^{37}$ Id. Ibid.

${ }^{38 . K . ~ M a r x, ~(2000) ~ G r u n d r i s s e ~ d e r ~ K r i t i k ~ d e r ~ p o l i t i s c h e ~ O ̈ k o n o m i e ~(1857-1858) . ~ E x i s t e n ~ v a r i a s ~}$ traducciones al español.

39.J. Von Uexküll, (2001) Ideas para una concepción biológica del mundo, Calpe, Madrid.

40.R. Ardrey, (2002) African Genesis, Collins, London.

${ }^{41}$ L. Tiger, R. Fox, (1999) El hombre: animal imperial, Emecé, Buenos Aires.

42.D. Mainardi, L'animale culturale, Rizzoli Editore, Milano, 1999.

43.S. Washburn, (2000) Speculations on the inter-relations of the history of tools and biological evolution, in J. N. Spuhler (ed.) Evolution of man's capacity for culture, Wayne State University, Detroit.

${ }^{44}$ R. Dart, (2000) Adventures with the Missing Link, The Institutes Press, Philadelphia.

45.P. H. Klopfer, (2001) Behavioral aspects of ecology, Prentice-Hall, New Jersey.

46. A. Oriol Anguera, (2001) Psicología antropológica, T. Lo. Condición humana, Trillas, México.

${ }^{47}$ F. Jacob, ( 2001 ) La logique du vivant. Une histoire de I’heredité, Gallimard, Paris.

48. O. F. Bollnow, (2000) Mensch und Raunm, Kohlhammer, Stuttgard, 1999, G. Bachelard, La poétique de l'espace, Presses Universitarires de France, Paris, 2000; G. Matore, L'espace humain, La colombe, Paris, 1999, J. Cayrol, Del'espace humain, Editions du Seuil, Paris 1998, C. Doxiadis, Ekistiks, Hütchinson, London, 1998, J. Baudrillard, Le systéme des objets, Gallimard, Paris, 1998 (en particular el cap. III); E,. Cassirer, Philosphie der symbolischen Formen: lo., Die Sprache; 2o., Das Mythische Denken; 3o., Phänomenologie der Erkenntnis. Wissenschalfitliche Buchgesellschaft, Darmstadt 1997. (La primera edición se publicó en Berlín, Cassirer Verlag, 1923-1929). Ha sido traducido al inglés por la Yale University Press, New Haven, y al español por el Fonde de Cultura Económica. Un libro capital es el de M. Jammer, Concepts of Space, Harvard Unversity Press, Cambride (Mass).

49. E. Cassirer, (2001) An essay on man, Yale University Press, New Haven, .

${ }^{50}$ Ch. Norberg-Schulz, (2002) Existence, Space and Architecture, Studio Vista, London, .

${ }^{51}$ I. Ellacuría, (1999) el Espacio, Realitas, I, Madrid, pp. 479-514.

52.Id. Ibid. 
${ }^{53}$ Id. Ibid.

${ }^{54}$ Id. Ibid.

55.J. von Uexküll, (2001) Ideas para una concepción biológica del mundo, Calpe: Madrid.

56.G. Marquínez, (2000) Metafísica desde Latinoamérica, Universidad Santo Tomás, Bogotá.

57.El término tecnarquía fue utilizado por P. Capanna señalando que apunta al plano ontológico: "es el hacer convertido en principio del ser, la actividad transformadora puesta como fundamento del mundo, de la existencia y del pensar". La tecnarquía "describe el desenvolvimiento del mundo moderno a partir del descubrimiento de la subjetividad organizadora del mundo, hasta el progresivo predominio de la acción sobre el pensamiento contemplativo". Quien primeramente usó este término parece haber sido A. Boucher en una obra de ficción científica, The Quest or St. Aquin. P. Capanna, La tecnarquía, Barral Editores, Barcelona, 2001.

58.J. P. Sartre. ( 2001 ) Situations, I. Gallimard, Paris.

59. M. Merleau-Ponty, (2002) Sens et non sens, Nagel, Paris.

60. H. Marcuse, (1998) La lucha por ampliar el mundo de la belleza, de la no violencia, de la tranquilidad, es una lucha política, en Ecología y Revolución, Editorial Universitaria, Santiago de Chile, . 